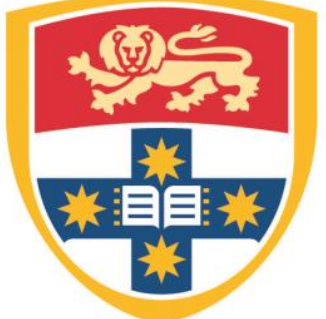

THE UNIVERSITY OF

SYDNEY

Economics Working Paper Series

$$
2016-20
$$

\author{
Inflation and \\ Real Wage Dispersion: \\ A Model of \\ Frictional Markets
}

Min Zhang and Stella Huangfu

March 2016 


\title{
Inflation and Real Wage Dispersion: A Model of
}

\section{Frictional Markets}

\author{
Min Zhang* \\ Shanghai University of Finance and Economics and, \\ Key Laboratory of Mathematical Economics (SUFE), Ministry of Education \\ Stella Huangfu ${ }^{\dagger}$ \\ University of Sydney
}

March 30, 2016

\footnotetext{
${ }^{*}$ We are thankful for the feedback received at various places where this paper was presented. We are also grateful to the editor and referees for the insightful comments. Min Zhang is thankful for financial support from the National Natural Science Foundation of China (Grant No. 71203132). Address correspondence to: Min Zhang, Shanghai University of Finance and Economics, School of Economics, 777 Guoding Road, Shanghai, China, 200433. Email address: zhang. min@mail.shufe.edu.cn.

†Email address: stella.huangfu@sydney.edu.au. Tel.: 6129036 9311. Mailing Address: School of Economics, University of Sydney, NSW, Australia, 2006.
} 


\begin{abstract}
Current Population Survey (CPS) data over the period from 1994 - 2008 shows that inflation has a positive effect on the residual wage dispersion. To explain this phenomenon, we introduce uncoordinated job searches into a general equilibrium monetary search framework. Our model shows that the uncoordinated job searches by unemployed workers give rise to an equilibrium where a firm is matched with zero, one or multiple job applicants. The ex post difference in matching probabilities generates a two-point wage dispersion among identical workers when the Mortensen rule is implemented in the wage determination process. In our model, inflation positively influences the wage dispersion directly through its impact on firm's real profit and indirectly through the effect of inflation that spills over from the goods market to the labor market. With reasonable parameter values, the calibrated model can account for most of the observed responses of residual wage dispersion to inflation.
\end{abstract}

JEL Categories: E40, J31

Keywords: Inflation, Residual Wage Dispersion, Uncoordinated Job Search, Spillover Effect 


\section{Introduction}

It is well documented in the labor literature that approximately two-thirds of the wage dispersion remains unexplained after controlling for observed characteristics of workers and jobs (Katz and Autor, 1999). Examining these large observed residual wage dispersions has been an extensively researched topic. Some search-based works explain the existence of the residual wage dispersion (among identical workers) as an equilibrium outcome. These studies assume on-the-job searches (Burdett and Mortensen, 1998; Kumar, 2008), heterogeneity in firms (Burdett et al., 2001; Shi, 2002; Postel-Vinay and Robin, 2002), or a two-track unemployment insurance benefits system (Albrecht and Vroman, 2001). Some other studies examine the relationship between inflation and wage dispersion. ${ }^{1}$ With the assumption of nominal wage rigidity, Sheshinski and Weiss (1977), Benabou (1988), and Diamond (1993) explain why inflation positively affects wage dispersion by using a $[s, S]$ strategy in wage settings. Cysne et al. (2005) propose an alternative explanation by assuming differentiated access to the transacting assets between the rich and the poor.

This paper connects these two streams of literature by studying the effect of inflation on residual wage dispersion. The empirical evidence based on Current Population Survey (CPS) data from the United States suggests that inflation has a positive effect on the residual wage dispersion. ${ }^{2}$ Following the labor literature, we calculate residual wage dispersion over the

\footnotetext{
${ }^{1}$ Some recent studies examine other determinants of wage/income dispersions. For example, GarciaPenalosa and Turnovsky (2015) examine the relationship between mobility and income inequality in a Ramsey model with elastic labor supply and heterogeneous wealth and ability. Kunieda et al. (2014) study how financial development affects inequality within a country.

${ }^{2}$ Existing empirical works that examine the relationship between inflation and wage dispersion are sparse and outdated, and the results are mixed. For instance, Hammermesh (1986) analyzes the relationship using 20 two-digit manufacturing industries for the 1955-1981 period in the United States. He finds that inflation reduces the dispersion in relative wage changes. Similar findings are reported for Italy by Erikson and Ichino (1995), who study metal-manufacturing firms over the 1976-1990 period. In contrast, a positive relationship is reported by Bulir (2001), who uses a cross-country database that includes 75 countries. He finds that the
} 
period from 1994-2008 after controlling for observed differences in workers and jobs. Our baseline measure is defined as $W D 90$, which is the ratio of high wages (the 90th percentile of the residual wage distribution) to low wages (the 10th percentile of the residual wage distribution). ${ }^{3}$ The estimation results indicate a positive elasticity of residual wage dispersion with respect to inflation. In the case of our baseline measure, when inflation is doubled, the residual wage dispersion increases by 2.22 percent. The positive elasticity result remains robust across alternative measures of wage dispersion.

To illustrate the positive empirical relationship between these two variables. Figure 1 in Appendix 7.1 shows the scatter plots between inflation and a variety of residual wage dispersion measures, namely four high-low wage ratios, the mean-min ratio, and the standard deviation of the residual wage distribution (to be discussed in details in Section 2). It is clear that there exists a robust and positive relationship between inflation and the residual wage dispersion. A similar message is delivered in Figure 2 in which we report the correlation between these two variables. For instance, in the case of $W D 90$, the correlation is 0.37 . The empirical evidence presented here suggests that inflation plays an important role in understanding the behavior of residual wage dispersion.

To explain the above-documented phenomenon, we develop a monetary search framework with uncoordinated job searches by workers. In the model, the uncoordinated job searches give rise to an equilibrium in which vacant firms are approached by zero, one or multiple job applications. The ex post difference in matching probabilities generates wage dispersion among identical workers. We propose a novel channel through which inflation positively positive effect is uniform for all levels of GDP per capita and is robust after controlling for redistributive policies.

${ }^{3}$ For robustness check purposes, we also examine alternative measures used in the literature. Our results are fairly close to the various measures reported in recent studies. Please see Section 2 for more details. 
affects the residual wage dispersion. In particular, in our model an increase in inflation affects wage dispersion directly through its effect on the real profits of firms in the goods market and indirectly through its effect on the matching probabilities in the labor market (the spillover effect). We show that the direct effect reduces both high wages and low wages. The indirect effect discourages job openings by firms, which places further downward pressure on low wages. As a result, low wages always decline more than high wages in response to an increase in inflation, and the resulting wage dispersion increases.

We contribute to the literature in two dimensions. First, we show that a two-point wage distribution can be generated among identical workers by taking into account the friction caused by the uncoordinated job searches of workers, which largely exists in the labor market, but receives little attention in the existing literature. As such, we view our paper as complementary to existing works on residual wage dispersion. Second, we highlight the role of the spillover effect of inflation in generating larger residual wage dispersion in episodes of high inflation. This spillover effect is emphasized by Berentsen et al. (2011) and is the driving force behind the positive effect of inflation on unemployment in their study. We show that the spillover effect is also important to understand the observed positive relationship between inflation and residual wage dispersion.

Uncoordinated job search is a key observation in labor markets. Taking into account this feature gives rise to ex post differences in matching probabilities among identical workers, which lead to wage dispersions in the model. Uncoordinated job search refers to a situation in which unemployed workers cannot coordinate in sending out their job applications due to information asymmetry problems, and thus randomize their applications over job positions. ${ }^{4}$

\footnotetext{
${ }^{4} \mathrm{~A}$ large number of empirical works examine the importance of information asymmetry in explaining
} 
The uncoordinated nature of the job search process implies that some vacant firms might attract more than one applicant, while others might not. Thus, an ex post dispersion in matching probabilities arises among ex ante identical workers, which leads to differences in the workers' outside opportunities and therefore in post-employment wages. Several theoretical papers, such as Ochs (1990) and Cao and Shi (2000), explore the importance of this lack-of-coordination problem in shaping the wage dispersion in a large frictional labor market where communication is incomplete or impossible. However, despite its popularity and importance, this feature has received little attention in the literature on the effect of inflation on wage dispersion. Our paper fills this gap.

In this paper, we implement the Mortensen rule proposed in Mortensen (1982) to generate wage dispersion among identical workers. Mortensen (1982) proposes an allocation rule in matching games that ensures efficiency. Specifically, the rule "allocates the total capital value of each match to the contacting agent less a compensation paid to the contacted agent equal to the latter's foregone value of continued search." According to the Mortensen rule, the contacted agent is indifferent between forming a match and his or her outside option. ${ }^{5}$ In our model, firms post vacancies looking for workers, while unemployed workers randomly apply for vacancies, ignorant of the decisions of other workers. Such a random search process implies that each firm may end up attracting zero, one (bilateral meeting) or many job applicants (multilateral meeting). In the case of a bilateral meeting, the firm is the contacted agent and the worker is the contacting agent. Applying the Mortensen rule suggests that the worker extracts the entire surplus from a match and thus receives high residual wage dispersion. For example, Montgomery (1991), Topa (2001), and Munish (2003).

${ }^{5}$ Julien et al. (2011) show how to implement the Mortensen rule as an equilibrium in a dynamic labor market. They argue that in settings where meetings can be multilateral, the Mortensen rule can be implemented as a local auction conducted by workers with firms search directed by posted reserve prices. 
wages. However, in the case of a multilateral meeting, one of the job applicants will be contacted by the firm to form an employment relation. Hence, the firm is the contacting agent and the worker is the contacted agent. As a result, the Mortensen rule allocates the entire surplus to the firm, and assigns the worker low wages.

The so-called spillover effect is crucial to generating an enlarged wage dispersion in response to an increase in inflation. The central insight is that the spillover effect makes low wages more responsive to changes in inflation. We show that in equilibrium, the low wages are a weighted average of the high wages and the value of the non-market activities of an unemployed worker (mainly unemployment insurance (UI) benefits in our model). In the context of high inflation, the real profits of firms decrease, which directly reduces the high wages (equal to real profits) and the low wages. In addition, the effect of inflation spills over from the goods market to the labor market in the following way: the decrease of the real profits in the goods market reduces the incentives for firms to post vacancies in the labor market, which creates a tighter labor market and makes it more difficult for workers to find jobs with high wages (fewer bilateral meetings). As a result, the low wages move closer to UI benefits. With a sufficiently low value of UI benefits, we show that the low wages further decrease. Thus, an increase in the inflation rate leads to a larger wage dispersion.

Confronting the model with CPS data from the United States, we show that our calibrated model is able to reproduce the observed elasticity of the residual wage dispersion with respect to inflation. In the baseline calibration, where the UI benefits $b$ are assumed to be zero, the predicted elasticity is 2.17 percent, which is fairly close to its empirical counterpart (2.22 percent) based on the measure of $W D 90$. Deviation from the baseline measure of wage dispersion does not qualitatively change the main results. When we set the UI benefits at 
the statutory replacement ratio of 0.4 as chosen by Shimer (2005) or at the effective UI replacement ratio of 0.25 as calculated in Zhang and Faig (2012), the model's fit decreases, but the model is still able to account for a large proportion of the observed response of residual wage dispersion to inflation. For example, in the case of $W D 90$, increasing $b$ to 0.25 reduces the predicted elasticity from 2.17 to 1.85 , and the model can account for 83.3 percent of the observed elasticity $(=1.85 / 2.22)$. A further increase to 0.4 decreases the predicted elasticity to 1.39 , while the model's explanatory power still remains sizable at approximately 62.6 percent. Finally, we deviate from the baseline calibration by increasing the markup ratio, the convexity of the cost function, and the elasticity of the real demand for money with respect to the nominal interest rate. We also impose alternative UI systems on the model economy. We find that the results remain robust, the elasticity of the residual wage with respect to inflation increases in most cases and slightly decreases in others.

Our paper builds on the work of Berentsen et al. (2011). Their framework provides explicit microfoundations for both money and unemployment and thus serves as a natural environment for studying the long-run relationship between monetary policy and labor market outcomes. We deviate from Berentsen et al. (2011) in the way we model job searches and the wage determination process to address the question of interest. Our work is closely related to that of Julien et al. (2006) in that both papers emphasize the role of the lack of coordination in accounting for wage dispersion. However, there are two main differences: First, their work focuses on uncoordinated searches by firms, while ours emphasizes this friction from the perspective of workers. Second, Julien et al. (2006) study why wage dispersion exists among identical workers, while our paper aims to examine the relationship between 
inflation and residual wage dispersion. ${ }^{6}$

The remainder of the paper is organized as follows. Section 2 documents the key facts characterizing the relationship between the residual wage dispersion and inflation for the period from 1994 to 2008. Section 3 develops a model featuring uncoordinated job searches by workers with wages determined through the Mortensen rule. Section 4 characterizes the equilibrium and presents the model's predictions for the impact of inflation on different wage levels and the resulting wage dispersion. In addition, the intuition of the results is discussed. Section 5 calibrates the model to the CPS data in the United States and quantifies the steady-state effect of inflation on wage dispersion. Section 6 concludes.

\section{Data and Facts}

Before we proceed to the data, it is worth noting that the model to be described in Section 3 predicts a two-point wage distribution in a model economy where both workers and firms are identical in all respects. To be consistent with the model, we measure residual wage dispersion in this section by using household-level data from the United States. That is, we calculate the residual wage dispersion by eliminating all wage variations caused by observed differences in workers and jobs.

The data we use are from the Current Population Survey (CPS). Starting in 1994, the CPS contains a variety of demographic characteristics, including age, sex, race, marital status, and educational attainment. Additionally, it contains useful information on jobs, such as

\footnotetext{
${ }^{6}$ Julien et al. (2006) also allow for heterogeneity in productivity in job vacancies to generate wage dispersion, whereas we abstract from this feature. However, we do take the effect of productivity on wage dispersion into account as we control for productivity in the estimation. Please see Section 2 for details.
} 
occupation and industry. This information enables us to precisely calculate measures of residual wage dispersion. We choose one quarter as a period and examine data from 19942008. ${ }^{7}$ Appendix 7.2 provides a description of the survey and the selection criteria we adopt. With regard to the measure of wages, we choose hourly wages from main jobs instead of monthly wages. By doing so, we take into account the fact that differences in monthly wages may reflect differences in hours worked.

To obtain the empirical relationship between wage dispersion and inflation, we analyze the data in two steps. First, we construct the measures of residual wage dispersion. Second, we examine the relationship between inflation and the residual wage dispersion. Following Hornstein et al. (2007), for every quarter in the period from 1994-2008, we run an OLS regression on an individual's nominal hourly wage (in log) where we control for gender, race, marital status, education, experience (age minus years of education minus five), industry, occupation, a dummy for union member, and the interaction between occupation and experience to capture occupation-specific tenure profiles. The regression gives us the residual nominal wage (in log) distribution for each quarter over the sample period. We then divide the residual nominal wage (in log) distribution by the consumer price index and use an exponent with a base of e to "undo" the logarithm. This procedure provides us the residual real wage (in level) distribution.

\footnotetext{
${ }^{7}$ We exclude the data before 1994 because the data on hourly wages (main job) that are used to construct the residual wage dispersion in this paper are not available until 1994. Only data on hourly earnings are available for the period from 1989-1993, which differ from the hourly wages (main job) in several respects. First, hourly earnings include hourly wages, tips, commissions, and other sources of income. Second, the question about hourly earnings could be answered by any member of a household, while hourly wages (main job) measure the wage rates received by the household head. Third, hourly earnings reflect earnings from all jobs, while hourly wages only carry information from the main job. Due to these differences, we exclude the data before 1994 .

The reason that we choose to examine data up to September 2008 is because the global financial crisis, which peaked in late 2008 and early 2009, resulted in a significant decline in economic activity and prolonged unemployment.
} 
We are now ready to calculate the measures of residual wage dispersion. Following the standard practice in the labor literature on wage dispersion, such as Card and DiNardo (2002), we use the ratio of the 90th percentile of residual wages to the 10 th percentile - the so-called 90 - 10 wage gap- as our baseline measure. Our measure of the residual wage dispersion (WD90) in quarter $t$ is then given by

$$
W D 90_{t}=\frac{\text { wage } 90_{t}}{\text { wage } 10_{t}}
$$

where wage90 and wage 10 are the 90 th and the 10 th percentile of the real residual wage distribution in quarter $t=1, \ldots, T$. The mean of the time series of $W D 90_{t}(t=1, \ldots, T)$ is 2.35 and is reported in the first column of Table 1.

\begin{tabular}{|c|c|c|c|c|c|c|}
\hline \multicolumn{7}{|c|}{ Table 1} \\
\hline \multicolumn{7}{|c|}{ Wage Dispersion (residual) } \\
\hline & $W D 90$ & WD 85 & $W D 80$ & $W D 75$ & Mean-min & S.D. \\
\hline Mean & 2.35 & 1.97 & 1.72 & 1.54 & 1.56 & 1.46 \\
\hline
\end{tabular}

NOTE: WD90, WD85, WD80, and WD75 are four measures of wage dispersion calculated as the ratio of high wages $(90 t h, 85 t h, 80 t h$ and $75 t h$ percentile of the residual wage distribution, respectively) to low wages (10th, 15th, $20 t h$ and $25 t h$ percentile of the residual wage distribution, respectively). Mean-min refers to the $50 t h-10 t h$ percentile wage gap. S.D. stands for the standard deviation of the real residual wage distribution.

Because both low wages and high wages are likely to be subject to outliers, as a check of robustness, we also examine three other measures of wage dispersion, namely, WD85, $W D 80$, and $W D 75$. They are the ratios of the high wages $(85 t h, 80 t h$, and $75 t h$ percentile of the residual wage distribution, respectively) divided by the corresponding low wages (15th, $20 t h$, and $25 t h$ percentile of the residual wage distribution, respectively). The next three columns of Table 1 present the mean of these three alternative measures, which range from 
1.97 to 1.54 . In the quantitative exercise conducted in Section 5, we use these four measures as targets for wage dispersion, with WD90 as our preferred measure.

Our measures of the high-low wage ratios prove to be consistent with other alternatives used in the literature. For example, we examine the mean-min ratio, which is calculated as the ratio of the $50 t h$ percentile of the residual wages to the $10 t h$ percentile. The mean-min ratio in our sample averages 1.56, which is fairly close to the estimates in recent works. For example, Hornstein et al. (2007) find mean-min ratios between 1.5 and 2 based on the November 2000 OES survey and the 1967-1996 waves of the PDIS survey. Acemoglu (2002), Lemieux (2006) and Autor et al. (2008) find mean-min ratios between 1.7 and 1.9 for male workers. In addition, we examine the standard deviation of the residual wage distribution. Card and DiNardo (2002) argue that this measure is fairly close to the measure of the $90-10$ wage gap, with differences mainly reflecting top-coding and the treatment of very low wage observations. In line with their argument, the mean of the standard deviation in our sample is approximately 1.46 , which is close to the $75-25$ percentile wage ratio of approximately 1.54. Table 1 summarizes all of the measures of wage dispersion discussed above.

Next, we examine the relationship between inflation and residual wage dispersion. To formally estimate the impact of changes in inflation on residual wage dispersions, we run the following regression $\log \left(Y_{t}\right)=\beta_{0}+\beta_{1}$ time $+\beta_{2} \log \left(\right.$ in flation $\left._{t}\right)+\beta_{3} \log \left(\right.$ productivity $\left._{t}\right)$, where $Y_{t}$ are the measures of residual wage dispersion constructed above. ${ }^{8} \quad \beta_{2}$ is the coefficient of interest, and it measures the elasticity of the residual wage dispersion with respect to inflation. Table 2 reports the regression results for our four measures of residual wage dispersion.

Table 2 shows that changes in inflation have a significant positive effect on residual wage dispersion in all cases. For example, in the case of $W D 75$, the elasticity of $W D 75$ with respect to inflation is approximately 0.0131, which suggests that if the inflation rate doubles, say from 2.74 (the mean over the sample period) to 5.48 percent, the wage dispersion will rise by 1.31 percent. In the case of $W D 90$, our preferred measure, the impact becomes stronger;

\footnotetext{
${ }^{8}$ We control for the time trend because both inflation and the residual wage dispersion are likely to change over time. Productivity is controlled for because a number of studies, such as Card and DiNardo (2002), argue that changes in productivity affect high wages and thus the wage dispersion. Following Shimer (2005), productivity is measured by output per worker in the business sector.
} 
with the same change in inflation, $W D 90$ increases by 2.22 percent. It is worth noting that although the estimated impact on the wage dispersion is moderate, it is significant and robust.

\section{Table 2}

Effects of Inflation on Residual Wage Dispersion

\begin{tabular}{|c|c|c|c|c|}
\hline \multirow[t]{2}{*}{ Variables } & \multicolumn{4}{|c|}{ Wage Dispersion (WD) } \\
\hline & $\log (W D 90)$ & $\log (W D 85)$ & $\log (W D 80)$ & $\log (W D 75)$ \\
\hline $\log ($ inflation $)$ & $\frac{0.0222^{* *}}{(0.0088)}$ & $\frac{0.0175^{* *}}{(0.0071)}$ & $\frac{0.0161^{* * *}}{(0.0059)}$ & $\frac{0.0131^{* *}}{(0.0050)}$ \\
\hline$R^{2}$ & 0.302 & 0.307 & 0.283 & 0.226 \\
\hline
\end{tabular}

NOTE: 1 . The regression takes the specification of $\log \left(Y_{t}\right)=\beta_{0}+\beta_{1}$ time $+\beta_{2} \log \left(\right.$ inflation $\left._{t}\right)+$ $\beta_{3} \log ($ productivity $)$, where $Y_{t}$ are the measures of the residual wage dispersion calculated as the ratio of high wages (90th, 85th, 80th and $75 t h$ percentile of the residual wage distribution, respectively) to low wages $(10 t h, 15 t h, 20 t h$ and $25 t h$ percentile of the residual wage distribution, respectively). 2. Standard errors in parentheses. 3. Asterisks stand for the significance level: ${ }^{* * *} \mathrm{p}<0.01,{ }^{* *} \mathrm{p}<0.05$.

\section{The Model}

Time is discrete, and agents are infinitely lived. Each time period is characterized by three distinct markets in which agents meet to conduct economic activities: a decentralized labor market (LM), a decentralized goods market (DM), and a centralized goods market (CM). The LM is designed in the spirit of the labor search theory of Mortensen and Pissarides (1994), and the DM is designed in the spirit of the monetary search theory of Lagos and Wright (2005). The CM functions as a clearing market. We assume that the markets open sequentially in each period, beginning with the LM and followed, in turn, by the DM and CM, as shown in Figure 3. All agents discount each time period at a uniform rate $\beta \in(0,1)$. Discounting occurs following CM activity and preceding LM activity.

There are two types of private agents: firms $(f)$ and workers $(h)$. The set of potential firms is arbitrarily large, and the set of workers is normalized to 1. Although all workers are continuously active in the model, some inactive firms always exist. Inactive firms may 
choose to become active at any time. Such firms enter the LM when it is possible to make positive economic profits. Workers provide labor and consume output to maximize their lifetime utility. Firms employ labor and sell their output to maximize profits, which are then paid as dividends to workers.

Money is intrinsically useless, perfectly divisible and storable. The quantity of fiat money per capita at the beginning of period $t$ is $M_{t}$. We assume that $M_{t+1}=(1+\pi) M_{t}$, where $\pi$ is constant and new money is injected by lump-sum transfers to workers in the CM. The price of goods in terms of money in the CM is $p_{t}$. We restrict our attention to steady-state equilibria in which the real value of aggregate money balances $M / p$ is constant, which implies that $p_{t+1}=(1+\pi) p_{t}$, and $\pi$ is the inflation rate between this and the next CM.

To facilitate the presentation of the model, we omit time indices and use $\hat{a}$ to denote the value of any variable $a$ in the next period. In addition, we convert all nominal variables into real terms in the following manner. When an agent enters the CM with $m$ dollars, we let $z=m / p$ denote his real balances. He then brings $\hat{z}=\hat{m} / p$ out of this market and into the next period, still deflated by $p$. The price level in the next CM is $\hat{p}$, so the real value of money is $\hat{z} \hat{\rho}$, where $\hat{\rho}=p / \hat{p}=1 /(1+\pi)$ converts $\hat{z}$ into the units of the numeraire in that market.

The value functions for the LM, DM and $\mathrm{CM}$ are $U_{e}^{j}, V_{e}^{j}$ and $W_{e}^{j}$, respectively. The value functions depend on agent type $j \in\{h, f\}$ and employment status $e \in\{0,1,2\}$, where $e=2$ indicates that the agent is currently in a high-wage contract in the LM, $e=1$ indicates that the agent is currently in a low-wage contract in the LM, and $e=0$ indicates that the agent is unmatched in the LM. The value functions also depend on other state variables that are defined below. In the discussion that follows, we consider a representative period $t$ and discuss the details of the three markets.

The LM: unemployed workers and vacant firms randomly search to establish employment relations. ${ }^{9}$ In each period, workers have one indivisible unit of labor service to sell to firms, and the firms are able to accommodate only one job applicant. ${ }^{10}$ If a worker and a firm

\footnotetext{
${ }^{9}$ It is standard in the search literature to assume random search in the model with homogenous workers and firms. Rogerson et al. (2005) provides a detailed survey on modelling strategies for the job search process.

${ }^{10}$ It is a standard assumption in the labor search literature that firms are capacity constrained. This
} 
form a match successfully, the match produces output $y$ immediately. The firm then sells the output in the DM and/or CM, and the wage is paid in the CM. The existing matches are subject to an exogenous separation shock at a rate $\delta$ in the LM.

At the beginning of a period, firms post vacancies looking for workers. Due to the lack of coordination in the job search, workers randomly choose to apply to one and only one vacancy and are ignorant of the decisions of other workers. The lack of coordination in the job search yields a match outcome where the unemployed firms could be approached by zero, one or multiple job applicants.

We implement the Mortensen rule here to generate a two-point wage dispersion among ex ante identical workers. Mortensen (1982) proposes an allocation rule that ensures efficiency in matching games. In particular, the rule allocates to the contacting agent the total surplus of a match net of the outside option value of the contacted agent. To understand this rule, consider a matching game where two types of agents, type 1 and type 2, meet to exploit some production opportunity that yields a capital value $B$. Suppose that the outside option values for type 1 and type 2 are $V_{1}$ and $V_{2}$, respectively. If the type 1 agent is contacted by the type 2 agent, that is, the type 2 agent is the contacting agent, or equivalently, the initiator of the match, according to the Mortensen rule, the type 2 agent receives $B-V_{1}$ : the surplus from forming the match $(B)$, net of the outside option value of the type 1 agent $\left(V_{1}\right)$. Meanwhile, the type 1 agent receives $V_{1}$ because he (the contacted agent) is indifferent between forming a match and his outside option, and vice versa.

In our model, in the case where the worker contacts the firm and forms a match immediately (bilateral meeting), the worker (contacting agent) extracts all of the gains from a match and receives a high wage $w^{h}$. As shown in Section 4.2, the high wage is the wage level such that the firm (contacted agent) is indifferent between employing the worker and not employing the worker (firm's outside option). In the case where more than one job candidate arrives at a firm (multilateral meeting), the firm randomly contacts one of the applying workers to form a match. Each applicant has an equal probability of success. In this case, the firm (contacting agent) receives all of the surplus and offers the worker a low wage $w^{l}$.

assumption is broadly consistent with what is observed in reality; a firm often receives many job applications but it can only accommodate one of them. 
We will show that the low wage is the wage level such that the successful job applicant (contacted agent) is indifferent between working and not working (worker's outside option). Unsuccessful applicants in multilateral meetings remain unemployed and receives UI benefits until the next period.

To summarize, the wage that a worker receives can take two possible values:

$$
w= \begin{cases}w^{h} & \text { bilateral meeting } \\ w^{l} & \text { multilateral meeting, if successful. }\end{cases}
$$

The DM: firms and workers randomly search for one another to trade consumption goods. Employed firms with output $y$ search for a worker to purchase firms' output or at least a proportion of the output. Workers, including those who are both employed and unemployed, carry fiat money and search for a firm from which to purchase consumption goods and enjoy utility. Once paired in the DM, the firm and the worker bargain over the terms of trade. The standard assumptions of monetary search theory are pivotal to the functioning of this market. Workers and firms are anonymous and meetings are quid pro quo. ${ }^{11}$

The $C M$ : agents trade in the centralized (Walrasian) market. Consumption goods that are not sold in the DM are transformed and transferred to the CM by firms that either searched without success in the DM or that found a match in the DM but did not sell their entire inventory. All income due by firms to workers (wages and dividends) is also paid in this market. Access to the centralized market during each period ensures the tractability of the model by causing the distribution of the money holdings of workers to degenerate.

\section{Workers}

A representative worker $h$ with employment status $e$ enters the CM with real balance $z$. Within the CM, $h$ maximizes utility with respect to the choice of consumption goods purchased, which is denoted by $x$, and the real balance to be carried into the next time

\footnotetext{
${ }^{11}$ Various assumptions can be made concerning price determination in the DM, including bargaining, price taking and price posting with directed searches. We focus on bargaining in this study because it is simple and standard in the literatures on monetary search.
} 
period, which is denoted by $\hat{z}$, to solve

$$
\begin{aligned}
W_{e}^{h}(z) & =\max _{x, \hat{z}}\left\{x+\beta U_{e}^{h}(\hat{z})\right\} \\
\text { s.t. } x+\hat{z} & =z+w_{e}+\Delta+\tau-T
\end{aligned}
$$

where $w_{e}$ is the real wage and

$$
w_{e}=\left\{\begin{array}{cc}
w^{h} & \text { if } e=2 \\
w^{l} & \text { if } e=1 \\
b & \text { otherwise }
\end{array}\right.
$$

Note that a wage is paid in the CM even though matching occurs in the LM. $b$ is the unemployment benefit provided by the government in real terms, and $b<w^{l}<w^{h}$. $\Delta$ is the dividend income that is derived from firm profits, and $T$ is a lump sum tax charged by the government. $\tau$ is a lump sum payment injected by the central bank in each period.

Inserting the budget constraint into (1) yields

$$
W_{e}^{h}(z)=I_{e}+z+\max _{\hat{z}}\left\{-\hat{z}+\beta \hat{U}_{e}^{h}(\hat{z})\right\}
$$

where $I_{e}=w_{e}+\Delta+\tau-T$ is the agent's after-tax income conditional on $e$. The assumption of quasi-linear utility is crucial here. Notice that $W_{e}^{h}$ is linear: $\partial W_{e}^{h} / \partial z=1$. Moreover, from (2), the optimal choice of $\hat{z}$ is clearly independent of $z$ and $I_{e}$ but does appear to depend on $e$ through $U_{e}^{h}$. However, as will be shown later, the utility function of the worker is independent of $e$, which makes the derivative of $\hat{U}_{e}^{h}$ and, hence, $\hat{z}$ independent of $e$. Thus, every worker brings the same $\hat{z}$ out of the CM. The assumption of a quasi-linear utility function makes the model become analytically tractable. ${ }^{12}$

In the DM, agents interact in a decentralized market with anonymous bilateral matching. Once matched, workers and firms bargain over the terms of trade $(q, d)$, where $q$ and $d$ are the units of goods and the real dollars exchanged, respectively. For $h$ with money holdings

\footnotetext{
${ }^{12}$ What complicates the analysis in monetary search models is the endogenous distribution of money holdings. An alternative way to make money holdings degenerate was proposed by Shi (1997). In his model, the fundamental decision-making unit is not an individual but a family with a continuum of agents. By law of large numbers, every household brings the same amount of money balances. See Lagos and Wright (2005) for a detailed discussion of these two approaches.
} 
$z$ and employment status $e$, the value function is

$$
V_{e}^{h}(z)=\alpha^{h}\left[v(q)+W_{e}^{h}(\rho z-\rho d)\right]+\left(1-\alpha^{h}\right) W_{e}^{h}(\rho z),
$$

where $\alpha^{h}$ is the probability of $h$ meeting a firm. We multiply any real balances taken out of the DM by $\rho$ to obtain their value in the CM. $v(q)$ is the utility, and we assume that $v(0)=0, v^{\prime}>0$ and $v^{\prime \prime}<0$.

The probability of trade is a matching function determined by the measure of workers and firms, denoted by $B$ and $S$, respectively, who are active in the DM. $\alpha^{h}=M(B, S) / B$. Matching function $M$ satisfies the usual matching function assumptions, including constant returns, $\alpha^{h}=M(Q, 1) / Q$, where $Q=B / S$ is the DM tightness. We assume that $M(Q, 1)$ is strictly increasing in $Q$, with $M(0,1)=0$ and $M(\infty, 1)=1$, and that $M(Q, 1) / Q$ is strictly decreasing, with $M(0,1) / 0=1$ and $M(\infty, 1) / \infty=0$. As all workers participate in the DM, $B=1$. Firms that are matched in the LM, those with $e=1,2$, participate in the DM; thus, $S=1-u$, where $u$ is the unemployment rate. The matching function can be written as $\alpha^{h}=M(1,1-u)$.

The analysis now progresses to the LM, in which the key features of this paper are located. In the LM, the value function for $h$ is constructed according to employment status

$$
\begin{gathered}
U_{e}^{h}(z)=\delta V_{0}^{h}(z)+(1-\delta) V_{e}^{h}(z), \text { where } e=1,2, \text { and } \\
U_{0}^{h}(z)=\lambda_{1}^{h} V_{1}^{h}(z)+\lambda_{2}^{h} V_{2}^{h}(z)+\left(1-\lambda_{1}^{h}-\lambda_{2}^{h}\right) V_{0}^{h}(z),
\end{gathered}
$$

where $\delta$ is the exogenous rate at which LM matches are destroyed. For simplicity, we assume that if a match is destroyed, $h$ cannot gain employment until the next LM meeting. $\lambda_{1}^{h}$ and $\lambda_{2}^{h}$ are the endogenous rates at which a worker enters a low-wage contract (the worker enters a multilateral meeting and is successfully chosen by the firm) and a high-wage contract (the worker enters a bilateral meeting with the firm), respectively. The matching rates, $\lambda_{1}^{h}$ and $\lambda_{2}^{h}$, depend on $u$ and $v$, where $u$ is unemployment and $v$ is the number of vacancies posted by firms.

This description completes the outline of the representative worker's one-period problem. 
The three value functions for $h$ can be collapsed into one Bellman equation. Substituting $V_{e}^{h}(z)$ from (3) into (4) and using the linearity of $W_{e}^{h}$ gives:

$$
\begin{aligned}
& U_{e}^{h}(z)=\alpha^{h}[v(q)-\rho d]+\rho z+\delta W_{0}^{h}(0)+(1-\delta) W_{e}^{h}(0), \text { where } e=1,2, \text { and } \\
& U_{0}^{h}(z)=\alpha^{h}[v(q)-\rho d]+\rho z+\lambda_{1}^{h} W_{1}^{h}(0)+\lambda_{2}^{h} W_{2}^{h}(0)+\left(1-\lambda_{1}^{h}-\lambda_{2}^{h}\right) W_{0}^{h}(0) .
\end{aligned}
$$

Inserting these into (2), in the steady state, the CM problem becomes

$$
\begin{aligned}
& W_{e}^{h}(z)=I_{e}+z+\beta\left[\delta \hat{W}_{0}^{h}(0)+(1-\delta) \hat{W}_{e}^{h}(0)\right]+\max _{\hat{z}}\left\{\beta \hat{\alpha}^{h}[v(\hat{q})-\hat{\rho} \hat{d}]-\hat{z}(1-\beta \hat{\rho})\right\}, \text { where } e=1,2, \text { and } \\
& W_{0}^{h}(z)=I_{0}+z+\beta\left[\lambda_{1}^{h} \hat{W}_{1}^{h}(0)+\lambda_{2}^{h} \hat{W}_{2}^{h}(0)+\left(1-\lambda_{1}^{h}-\lambda_{2}^{h}\right) \hat{W}_{0}^{h}(0)\right]+\max _{\hat{z}}\{\beta \hat{\alpha} h[v(\hat{q})-\hat{\rho} \hat{d}]-\hat{z}(1-\beta \hat{\rho})\} .
\end{aligned}
$$

Note that the choice of $\hat{z}$ of the worker does not depend on $e$.

\section{Firms}

We now consider the problem of the representative firm $f$. Before proceeding to the markets, we must emphasize that only firms with $e=1,2$ require money to pay wages and dividends in the CM. The money that is necessary for wage and dividend payments is raised each period in the DM and/or CM markets. Thus, $f$ with $e=0,1,2$ has no need to carry money from the CM. Considering the LM first, the value function of $f$ is

$$
\begin{gathered}
U_{e}^{f}=\delta V_{0}^{f}+(1-\delta) V_{e}^{f}, \text { where } e=1,2, \text { and } \\
U_{0}^{f}=\lambda_{1}^{f} V_{1}^{f}+\lambda_{2}^{f} V_{2}^{f}+\left(1-\lambda_{1}^{f}-\lambda_{2}^{f}\right) V_{0}^{f},
\end{gathered}
$$

where $\lambda_{1}^{f}$ and $\lambda_{2}^{f}$ are the endogenous rates at which active yet vacant firms enter low- and high-wage contracts, respectively. Again, the matching rates $\lambda_{1}^{f}$ and $\lambda_{2}^{f}$ are functions of the LM variables $u$ and $v$.

Participation for $f$ in the DM and CM requires $e=1,2$. If $e=1,2$, then $f$ carries output $y$ to the DM and sells a quantity $q$, where $q \in[0, y]$. The residual $y-q$ is transformed into $x=\zeta(y-q)$ units of the CM goods and sold in the subsequent CM with $\zeta^{\prime} \geq 0$ and $\zeta^{\prime \prime}<0$. The opportunity cost of sale is defined as $c(q)=y-\zeta(y-q)$. Unless otherwise stated, we 
assume that $\zeta$ is linear such that $x=y-q$ and $c(q)=q$. For a firm entering the DM with $e=1,2$,

$$
V_{e}^{f}=\alpha^{f} W_{e}^{f}(y-q, \rho d)+\left(1-\alpha^{f}\right) W_{e}^{f}(y, 0)
$$

where $\alpha^{f}=M(B, S) / S=M(1 /(1-u), 1)$ is the probability of $f$ meeting and trading with a worker in the DM. $W_{e}^{f}(x, z)$ for $e=1,2$ is the value of entering the CM with $x$ units of the CM consumption goods and $z$ in cash receipts. The value function for $f$ with $e=1,2$ entering the $\mathrm{CM}$ is

$$
W_{e}^{f}(x, z)=x+z-w_{e}+\beta \hat{U}_{e}^{f}
$$

where $w_{e}$ for $e=1,2$ is the real wage paid by $f$. Simplifying the expression, we obtain

$$
V_{e}^{f}=R-w_{e}+\beta\left[\delta \hat{V}_{0}^{f}+(1-\delta) \hat{V}_{e}^{f}\right], \text { for } e=1,2,
$$

where $R=y+\alpha^{f}(\rho d-q)$ is the expected real revenue that an employed firm earns during each period. This expression indicates that the expected real revenue is identical for $e=1,2$.

A firm with $e=0$ has no wage obligations and has no output to sell. Such a firm is considered to be inactive. An inactive firm is able to enter the next LM only if it pays a real cost, denoted by $k$, incurred in the prior CM. Thus,

$$
W_{0}^{f}=\max \left\{0,-k+\beta\left[\lambda_{2}^{f} \hat{V}_{2}^{f}+\lambda_{1}^{f} \hat{V}_{1}^{f}+\left(1-\lambda_{1}^{f}-\lambda_{2}^{f}\right) \hat{V}_{0}^{f}\right]\right\}
$$

where $\hat{V}_{0}^{f}=\hat{W}_{0}^{f}=0$ by free entry. In the steady state, $k=\beta\left(\lambda_{2}^{f} V_{2}^{f}+\lambda_{1}^{f} V_{1}^{f}\right)$. By (6), $k$ can be expressed as

$$
k=\frac{\beta}{1-\beta(1-\delta)}\left[\lambda_{1}^{f}\left(R-w^{l}\right)+\lambda_{2}^{f}\left(R-w^{h}\right)\right]
$$

\section{Government}

The government records a balanced budget in each period. The government collects lump sum taxes from workers, denoted by $T$; consumes $G$; pays an unemployment benefit to $h$ with $e=0$, denoted by $b$; and prints money at rate $\pi$ such that $\hat{M}=(1+\pi) M$, where $\pi$ is the steady-state inflation. In the budget constraint for $h$ in the $\mathrm{CM}, \tau=\pi M / p$. New money is injected as lump-sum transfers to workers in the CM. We assume that the government 
budget constraint is $G+b u=T+\pi M / p$.

Because we focus on the steady-state analysis, by the Fisher equation $1+i=(1+\pi) / \beta$, we can equivalently describe the monetary policy in terms of setting the nominal interest rate $i$ or the growth rate of money $\pi$. We always assume $i>0$, although we do consider the limit as $i \rightarrow 0$, which is the Friedman rule. ${ }^{13}$

\section{Equilibrium}

\subsection{The Goods Market}

As noted previously, $f$ and $h$ meet and bargain bilaterally over $(q, d)$ in the DM. Let $\theta \in(0,1]$ denote the bargaining power of $h$. The surplus for $h$ is $v(q)+W_{e}^{h}(\rho z-\rho d)-W_{e}^{h}(\rho z)=$ $v(q)-\rho d$, by using the linearity of $W_{e}^{h}(z)$. Similarly, the surplus for $f$ is $\rho d-q$. Thus, the Nash bargaining problem is

$$
\max _{q, d}[v(q)-\rho d]^{\theta}[\rho d-q]^{1-\theta}
$$

s.t. $d \leq z$ and $q \leq y$, which says that the parties cannot leave with negative cash balances or inventories. Without a loss of generality, we assume that $q<y$. The solution of (8) depends on $z$ if and only if the constraint $d \leq z$ binds. If it does not bind, then $q=q^{*}$, where $v^{\prime}\left(q^{*}\right)=1$ and $d=(1-\theta) v\left(q^{*}\right)+\theta q^{*}$. However, as established in Lagos and Wright (2005), in any monetary equilibrium, $h$ will spend all of his cash holdings so $d=z \cdot{ }^{14}$ Then, $q$ solves the first-order condition from (8) with $d=z$, which we can write as

$$
\rho z=g(q) \equiv \frac{\theta v^{\prime}(q) q+(1-\theta) v(q)}{\theta v^{\prime}(q)+1-\theta}
$$

We are now able to use what we know about the bargaining solution to solve the equilibrium in the DM. Using equation (5), which is essentially the key equation of the CM and then (i) inserting $\hat{d}=\hat{z}$ and $\partial \hat{q} / \partial \hat{z}=\hat{\rho} / g^{\prime}(\hat{q})$ by virtue of (9), (ii) using the Fisher equation

\footnotetext{
${ }^{13}$ Our qualitative results still hold at the Friedman rule. Derivations are available upon request.

${ }^{14}$ Intuitively, $d=z$ follows from a simple arbitrage argument — why bring more money than you are ever going to spend? Please see Appendix 7.3 for the proof.
} 
for the nominal interest rate to eliminate $1 /(\beta \hat{\rho})=1+i$, (iii) inserting the arrival rate $\hat{\alpha}^{h}=M(1,1-\hat{u})$, and (iv) imposing a steady state, we arrive at

$$
\frac{i}{M(1,1-u)}=\frac{v^{\prime}(q)}{g^{\prime}(q)}-1 .
$$

We refer to equation (10) as the DM curve. Simple conditions guarantee the existence of a unique monetary equilibrium with $q>0$ given any $u .{ }^{15}$ Routine calculations show that for $i>0$, the DM curve slopes downwards in $(u, q)$ space for exactly the same reasons as those cited in Berentsen et al. (2011): for higher values of $u$, there are fewer firms with output to sell in the DM; therefore, $\alpha^{h}$ decreases. The terms of trade may also be adversely affected for workers as the number of firms selling consumption goods decreases. These effects are aggregated to reduce the demand for real money balances $z$ and thus to reduce the amount of goods traded $q$ via the bargaining solution.

Another important result from (10) is that $q<q^{*}$ for all $i>0$, where $q^{*}$ is the efficient amount of goods traded, defined as $v^{\prime}\left(q^{*}\right)=1$. In other words, the steady state is efficient if and only if $i=0$ and $\theta=1$. Intuitively, there are two types of inefficiencies. First, workers do not always find a trading partner in the goods market. When it is costly to hold money, workers choose to carry less than the efficient amount. In the second type of inefficiency, the choice of firms to bargain away part of the trading surplus also reduces the incentive to hold money.

\subsection{The Labor Market}

To solve the labor market equilibrium condition (7) in terms of $(u, q)$, we must first calculate the two wage levels $w^{h}$ and $w^{l}$. As previously stated, the high wage in equilibrium is the wage level at which the firm (the contacted agent in a bilateral meeting) is indifferent between making a high-wage employment offer to a worker and not employing the worker: $V_{2}^{f}=V_{0}^{f}$. By contrast, the low wage is the wage level at which a successful candidate (randomly contacted by the firm among many job applicants in a multiple meeting) is indifferent between employment status $e=1$ and $e=0: V_{1}^{h}=V_{0}^{h}$. These two conditions allow us to solve $w^{h}$

\footnotetext{
${ }^{15}$ Wright (2010) provides a detailed discussion regarding the existence of a unique monetary equilibrium.
} 
and $w^{l}$ as a function of $(u, q)$. The results are

$$
\begin{gathered}
w^{h}=R=y+\alpha^{f}[g(q)-q], \text { and } \\
w^{l}=\frac{1-\beta(1-\delta)}{1-\beta\left(1-\delta-\lambda_{2}^{h}\right)} b+\frac{\beta \lambda_{2}^{h}}{1-\beta\left(1-\delta-\lambda_{2}^{h}\right)} w^{h} .
\end{gathered}
$$

Intuitively, in a bilateral meeting where a vacant firm is approached by exactly one candidate, the firm is obliged to hire that candidate. The outside option of the firm is zero. As the Mortensen rule suggests, the candidate who initiates the match receives a wage $w^{h}$ that is equal to the entire value of the match $R$. If, alternatively, any other candidate also visits that firm, then the wage will be negotiated up to its full valuation from the point of view of the firm. In this case, the payoff to the worker is his continuation value (whether he actually accepts the job offer or not). The low wage $w^{l}$ is a weighted average of workers' outside value $b$ and the high wage $w^{h}$ (which is equal to a firm's revenue $R$ ). It is easy to check $b<w^{l}<w^{h}$.

Substituting the two wage levels expressed in (11) and (12) into the free entry condition (7) and then inserting $\rho d-q=g(q)-q$ by virtue of (9), we obtain

$$
\frac{k}{\beta}=\frac{\lambda_{1}^{f}}{1-\beta\left(1-\delta-\lambda_{2}^{h}\right)}\left[y+\alpha^{f}(g(q)-q)-b\right] .
$$

This equation is the general expression for the LM curve. To map the curve in $(u, q)$ space, we must define the matching functions $\lambda_{1}^{f}, \lambda_{2}^{f}, \lambda_{1}^{h}$ and $\lambda_{2}^{h}$.

Consider a worker who is unemployed. If $v$ vacancies are posted in the labor market, then the probability that a worker randomly visits any particular searching firm is $1 / v$ and the probability that the worker does not approach a certain firm is $1-1 / v$. Then, the probability that the firm is not approached by any unemployed workers is $(1-1 / v)^{u}$ and the probability that exactly one worker approaches the firm in the labor market, defined as the matching rate $\lambda_{2}^{f}$, is $\phi(1-1 / v)^{u-1}$, where $\phi=u / v$ is defined as labor market tightness. $\lambda_{1}^{f}$, the probability that more than one worker visits the firm in the labor market, is $1-(1-1 / v)^{u}-\phi(1-1 / v)^{u-1}$.

For an unemployed worker to enter a high-wage contract, the worker must be the sole applicant at the firm to which he or she visits. The probability that the worker is the 
sole applicant is the probability that no other workers visit the firm. Hence, $\lambda_{2}^{h}$ is equal to $(1-1 / v)^{u-1}$. The probability of the worker entering a low-wage contract, $\lambda_{1}^{h}$, is the probability of at least two workers arriving at the same firm, $1-(1-1 / v)^{u}-\phi(1-1 / v)^{u-1}$, divided by the number of applicants. The average number of applicants at a firm is best approximated by $\phi$. Therefore, $\lambda_{1}^{h}=\left(1-(1-1 / v)^{u}-\phi(1-1 / v)^{u-1}\right) / \phi$.

This paper considers the effect of inflation on wage dispersion in a large economy by holding $\phi$ constant and examining the case in which $v$ is a large but finite number. In this type of environment, the economy can be closely approximated by the limit economy in which $v \rightarrow \infty$. Using the rule that $\lim _{v \rightarrow \infty}(1+x / v)^{v}=e^{x}$, the labor market matching functions are,

$$
\begin{gathered}
\lambda_{2}^{f}=\lim _{v \rightarrow \infty} \phi(1-1 / v)^{v \phi-1}=\phi e^{-\phi}, \\
\lambda_{1}^{f}=\lim _{v \rightarrow \infty} 1-\phi(1-1 / v)^{v \phi-1}-(1-1 / v)^{v \phi}=1-\phi e^{-\phi}-e^{-\phi}, \\
\lambda_{2}^{h}=\lim _{v \rightarrow \infty}(1-1 / v)^{v \phi-1}=e^{-\phi}, \text { and } \\
\lambda_{1}^{h}=\lim _{v \rightarrow \infty} \frac{1-(1-1 / v)^{v \phi}-\phi(1-1 / v)^{v \phi-1}}{\phi}=\frac{1-e^{-\phi}-\phi e^{-\phi}}{\phi} .
\end{gathered}
$$

Finally, the dynamics of unemployment follow from the law of motion:

$$
(1-u) \delta=u\left(\lambda_{1}^{h}+\lambda_{2}^{h}\right)
$$

Equation (15) implies a downward-sloping Beveridge curve, that is, $\partial v / \partial u<0$, which also suggests that a higher rate of unemployment increases labor market tightness $(\partial \phi / \partial u>0)$. Using equation (15) we could solve for and insert $v=v(u)$ into the above matching functions.

Substituting the matching functions (14) into equation (13), we obtain the final specification of the LM curve:

$$
\frac{k}{\beta}=\frac{1-e^{-\phi}-\phi e^{-\phi}}{1-\beta\left(1-\delta-e^{-\phi}\right)}\left\{y+M\left(\frac{1}{1-u}, 1\right)[g(q)-q]-b\right\},
$$

where $\phi$ is now $u / v(u)$ by using (15). This LM curve determines $u$ by taking the value of $q$ as given. Here, we assume that $k<\beta\left[y-b+g\left(q^{*}\right)-c\left(q^{*}\right)\right] /[1-\beta(1-\delta)]$ because, otherwise, it is too costly for firms to enter and the labor market would simply shut down. 
Differentiating (16) provides the solution that $d q / d u$ is negative. The LM curve slopes downward in $(u, q)$ space. The intuition for this result is simple. There are two general effects of an increase in $u$ : first, firms and workers are more likely to enter multilateral meetings, so $\lambda_{1}^{f}$ increases and $\lambda_{2}^{h}$ decreases; second, it is easier for firms to compete in the DM, so $\alpha^{f}$ increases. These two effects encourage the entry of firms. Thus, the equilibrium value of $q$ must be reduced to ensure that the free entry condition holds.

\subsection{General Equilibrium}

We now characterize equilibria. Here is an outline of what will follow, first, we determine the quantity of goods traded in the $\mathrm{DM} q$, taking unemployment $u$ as given. We then determine $u$, taking $q$ as given, as in Mortensen-Pissarides (1994). It is convenient to depict these two relationships graphically in $(u, q)$ space by what we call the DM curve (equation (10)) and the LM curve (equation (16)). The intersection of the DM and LM curves determines the equilibrium unemployment rate and the quantity of goods $(u, q)$, from which all other endogenous variables, including the real wages $w^{l}$ and $w^{h}$, can be easily recovered.

Definition 1 Given a money supply process, $\hat{M} / M=1+\pi$, a stationary monetary equilibrium is a sequence of value functions $\left(U_{e}^{j}, V_{e}^{j}, W_{e}^{j}\right)$ for $e \in\{0,1,2\}$ and $j \in\{h, f\}$, the wage levels $\left(w^{h}, w^{l}\right)$ in the LM, the terms of trade in the DM $(q, d)$, the price (p) and the decision rule for real money holdings $(\hat{z})$ in the CM, such that

(i) given prices, the value functions satisfy equations (2), (3) and (4);

(ii) with $d=z$ and $q>0$, the terms of trade $(q, d)$ maximize equation (8);

(iii) the decision rule ( $\hat{z}$ ) satisfies equation (9), and $p$ is the solution to $\hat{z}=\hat{M} / p$;

(iv) the wage levels $\left(w^{h}, w^{l}\right)$ satisfy equations (11) and (12).

Figure 4 maps the DM and LM curves in a box $B=[0,1] *\left[0, q^{*}\right]$ in $(u, q)$ space. The DM curve enters $B$ from the left at $\left(0, q_{0}\right)$, where $q_{0} \leq q^{*}$, and it exits at $(1,0)$. Further calculations confirm that the DM curve is concave in B. The LM curve enters B from the top at $\left(u_{0}, q^{*}\right)$. If $k<\beta(y-b) /(1-\beta(1-\delta))$, then it exits from the bottom at $\left(u_{1}, 0\right)$ (see the curve labelled LM1). In this case, a non-monetary equilibrium exists at $\left(u_{1}, 0\right)$, 
and at least one monetary equilibrium also exists. If $k \geq \beta(y-b) /(1-\beta(1-\delta))$, then the LM curve exits $\mathrm{B}$ from the right at $\left(1, q_{1}\right)$. In this case, a non-monetary equilibrium exists at $(1,0)$, and depending on the parameter values, monetary equilibria may also exist (see the curves labelled LM2 and LM3). Generally, we do not have uniqueness. Monetary and non-monetary equilibria may coexist. However, a monetary equilibrium may be unique, as in the calibrations below.

Proposition 1 Steady-state monetary equilibrium exists. If $k<\beta(y-b) /(1-\beta(1-\delta))$, then at least one monetary steady state exists in which $q<q^{*}$ and $0<u<1$. If $k \geq$ $\beta(y-b) /(1-\beta(1-\delta))$, then a non-monetary steady state exists at $(1,0)$, and depending on the parameter values, monetary steady states may also exist. If the monetary steady state is unique, then an increase in $i$ causes a decrease in $q$ and an increase in $u$.

The inequality $k<\beta(y-b) /(1-\beta(1-\delta))$ simply says there would be entry into the LM even if we shut down the DM. In this case, there exists a nonmonetary steady state equilibrium at $\left(u_{1}, 0\right)$, which is exactly the standard Mortensen-Pissarides equilibrium, and there exists at least one monetary steady state with $q>0$ and $u<u_{1}$.

In monetary equilibrium, an increase in inflation will not affect the LM curve but will shift the DM curve toward the origin. Therefore, an increase in the rate of inflation causes a decrease in $q$ and an increase in $u$. The result $\partial q / \partial i<0$ is standard in monetary search models: inflation is a tax on cash-intensive activity. The result $\partial u / \partial i>0$ is important in the sense that there is no role for monetary policy in the Mortensen Pissarides model. Intuitively, households reduce their holding of real balances as inflation increases, which hurts profits in the goods (retail) market and in turn discourages entry and job creation; thus, unemployment increases.

\subsection{Results}

We now consider the effect of inflation on the wage dispersion. Formally, we define the wage dispersion as the ratio between the high wage $w^{h}$ and the low wage $w^{l}$.

$$
W D=\frac{w^{h}}{w^{l}}
$$


Differentiating (17) with respect to $i$ yields mixed result. The sign of the result depends on the value of the UI benefits $b$ (see the discussion below Proposition 2 for the explanation). However, we can prove that $\partial(W D) / \partial i>0$ holds when the values of $b$ approach zero. In Section 5, we will show numerically that with plausible values of $b$ calibrated to the United States economy, an increase in inflation does increase the wage dispersion, which is consistent with what is observed in the data.

Proposition 2 As the UI benefits approach zero, an increase in the rate of inflation increases the wage dispersion. Moreover, although both high and low wages decline with inflation, the negative effect is always stronger on the low wage than on the high wage.

Proposition 2 proposes an explanation for how inflation raises the wage dispersion. The intuition is as follows. From Equation (11), it is evident that when inflation increases, the quantity of goods traded in the DM declines (Proposition 1), which leads to a decrease in the trade surplus $g(q)-q$. As the trade surplus decreases, firms post fewer vacancies in the LM, and the steady-state rate of unemployment increases. The labor market becomes tighter: the $u / v$ ratio increases. Following Berentsen et al. (2011), we refer to this effect as a spillover effect (a spillover from the goods market to the labor market). This effect, in turn, increases the ease with which firms (sellers) meet workers (buyers) in the DM; thus, $\alpha^{f}$ increases. Therefore, the expected trade surplus tends to increase. However, as suggested by the results, the decrease in $g(q)-q$ always dominates the increase in $\alpha^{f}$; therefore, the overall effect on the real profits of firms from the DM trades is negative. Note that the high wage is equal to the real profit. It follows that the high wage decreases in reaction to increases in inflation.

With regard to the low wage $w^{l}$, there are two forces that make $w^{l}$ decline more than $w^{h}$. From Equation (12), it is evident that the low wage is a weighted average of the high wage $w^{h}$ and a worker's outside option $b$. The first force comes from the decline in the high wage, which pushes down the low wage directly. The second force operates indirectly through the spillover effect. With higher inflation, the spillover effect leads to a tighter labor market, resulting in a lower likelihood of finding high-wage jobs for workers (a lower chance of forming bilateral meetings). Thus, $\lambda_{2}^{h}$ decreases. The decline in $\lambda_{2}^{h}$ affects the weights 
of $b$ and $w^{h}$ differently; the decrease in $\lambda_{2}^{h}$ increases the weight of $b$, which moves the low wage toward the value of $b$. Thus, the first term in Equation (12) increases. In contrast, the decrease in $\lambda_{2}^{h}$ lowers the weight assigned to $w^{h}$, which, together with a reduced $w^{h}$, places a downward pressure on the low wage. Thus, the second term in Equation (12) decreases. The overall effect of the spillover effect on the low wage depends on the relative strength of these two opposing changes, which ultimately depends on the value of $b$. To see this, consider the extreme case where $b=0$. In this case, the first term in Equation (12) disappears. Both forces, the declining high wage and the spillover effect, contribute to decreasing $w^{l}$. As a result, the low wage declines more than the high wage, and the wage dispersion becomes larger. In the general case where $b$ is positive, the spillover effect becomes weaker due to the two opposing changes. However, as long as the value of $b$ is sufficiently small such that the decrease in the second term dominates the increase in the first term, the spillover effect remains negative, and the result that the wage dispersion positively responds to inflation remain valid.

\section{$5 \quad$ Numerical Analysis}

This section aims to quantify the steady-state effect of inflation on the wage dispersion. To conduct this exercise, we first calibrate the model constructed in Section 3 to match several features of labor and goods markets in the United States. In particular, we calibrate the model in such a way that it can generate the observed wage dispersion reported in Section 2. The calibrated model is then used to evaluate the influence of a change in inflation on the wage dispersion. Our simulation results show that the model implications are quantitatively consistent with the empirical evidence observed in the United States.

As in much of the macro-labor literature, the numerical analysis in this section uses the following specifications. In the DM, the utility function assumes the functional form of $v(q)=A q^{1-a} /(1-a)$, and the transformation cost function is $c(q)=q^{\gamma}$. The matching function in the DM (goods market) is assumed to be $M(B, S)=B S /(B+S)$. Thus, the matching probabilities of buyers (workers) and sellers (firms) are: $\alpha^{h}=M(B, S) / B=$ $(1-u) /(2-u)$, and $\alpha^{f}=M(B, S) / S=1 /(2-u)$. Given these specifications, the para- 
meters to be determined include preference parameters $(\beta, A, a)$, the technology parameters $(y, k, \delta, \gamma, \theta)$ and the policy parameter $b$.

\subsection{Parameterization}

The model period is set to be one quarter. The calibration targets that we choose are standard in the literature. The discount factor $\beta$ is set to match the annual real interest rate, which is 4.8 percent. In the model, the real demand for money $M /(p Y)$ is measured by

$$
\frac{M}{p Y}=\frac{g(q)}{(1-u)\left\{\alpha^{f}[g(q)-c(q)]+y\right\}} .
$$

The scale parameter $A$ and the curvature parameter $a$ in the utility function jointly determine the value of $M /(p Y)$ through the function of $g(q)$; therefore, these two parameters are set to target the average real demand for money and its reaction to changes in the nominal interest rate (elasticity), which are 0.179 and -0.556 , respectively, as reported by Berentsen et al. (2011). As we focus on the steady-state analysis, the productivity in a formed match is normalized to one. The flow cost of posting a vacancy $k$ is determined to match the observed wage dispersions as calculated by $w^{h} / w^{l}$. Table 2 shows that the reactions of the wage dispersion to inflation vary across different measures, with largest for the measure of $W D 90$ and the smallest for the measure of $W D 75$. To examine whether the calibrated model can reproduce various responses, we use four measures of percentile wage ratios ( $W D 90 / W D 85 / W D 80 / W D 75)$ as the target for $k$ in the calibration. ${ }^{16}$ The exogenous job separation rate $\delta$ is set to 0.1 at quarterly frequency, which is consistent with the quarterly average of the monthly rate of 0.033 calculated in Shimer (2005). The curvature parameter in the cost function $\gamma$ is set to one in the baseline calibration. The bargaining power of buyers in the DM $\theta$ shows up in the function of $g(q)$, which determines the profit rate in the DM. Hence, the value of $\theta$ is chosen to match the mark-up ratio, which is 30 percent, as summarized by Faig and Jerez (2005). In the model, the mark-up ratio is measured

\footnotetext{
${ }^{16}$ It is worthwhile to point out that with a two-point wage distribution in our model it is more appropriate to use the high-low wage ratios as calibration targets rather than the alternative measures, such as the mean-min ratio or the standard deviation of the residual wage distribution.
} 
by

$$
\text { markup }=100\left(\frac{g(q)}{c^{\prime}(q) q}-1\right) .
$$

For the policy parameter $b$, according to Proposition 2 in Section 4, when the UI benefits approach zero, the wage dispersion as measured by $w^{h} / w^{l}$ unambiguously increases with inflation. We set the value of $b$ to be zero in the baseline calibration. In the robustness check, we will consider two alternative values to examine how sensitive the model's predictions are to the choice of $b$. One value is the statutory UI replacement ratio, $b=0.4$, as chosen by Shimer (2005). The other value, $b=0.25$, is the effective UI replacement ratio calculated by Zhang and Faig (2012). Zhang and Faig (2012) take into account the fact that some unemployed workers who are entitled to benefits do not actually claim UI. To address this issue, they construct the effective UI replacement ratio as the product of the take-up rate (the proportion of eligible unemployed workers who actually claim UI) and the observed replacement rate conditional on receiving benefits. As documented by Blank and Card (1991), the takeup rate over the period from 1977-1987 was fairly stable at approximately 0.7, while the replacement rate conditional on receiving benefits averaged 0.357 over the period from 1972 2003, as reported by Zhang and Faig (2012); this calculation yields $b=0.25 .^{17}$

Table 3 reports the targets used in the baseline calibration. The values $\{\beta, y, \delta, \gamma, b\}$ follow directly from the stated targets in the table. The remaining parameters $\{A, a, k, \theta\}$ are calibrated from the following iterative procedures. The steady-state values of $\{u, q\}$ are the solution to the system of equations that contain Equations (10) and (16). With some initial guesses for $\{A, a, k, \theta\}$, we fit the observed nominal interest rate over the sample period into the system of equations, solve for the equilibrium values of $\{u, q\}$ and verify that the predictions of the model match the last four listed targets in Table $3 .^{18}$ If the predictions do not match, then the initial guess is revised, and the above process is repeated until the predictions from the calibrated model match well with all of the targets.

\footnotetext{
${ }^{17}$ Faig et al. (2015) use the same value of $b$ in their study.

${ }^{18}$ The nominal interest rates that we use here are AAA Corporate Bond rates.
} 
Table 3

Baseline Parameterization

\begin{tabular}{lllr}
\hline Variables & & Target Descriptions & Target Values \\
\hline Discount factor & $\beta$ & annual real interest rate & 0.048 \\
Productivity in a formed match & $y$ & normalization & 1 \\
Separation rate & $\delta$ & monthly job separation rate in Shimer $(2005)$ & 0.033 \\
Curvature parameter in $c(q)$ & $\gamma$ & normalization & 0 \\
UI benefits & $b$ & normalization & 0.179 \\
Scale parameter in $v(q)$ & $A$ & real demand for money in Berentsen et al. $(2011)$ & -0.556 \\
Curvature parameter in $v(q)$ & $a$ & elasticity of money demand w.r.t. $i$ in Berentsen et al. $(2011)$ & $2.35 / 1.97 / 1.72 / 1.54$ \\
Flow cost of posting a vacancy & $k$ & residual wage dispersions calculated by authors & 0.30 \\
Bargaining power in DM & $\theta$ & mark-up ratio in Faig and Jerez $(2005)$ & \\
\hline \hline
\end{tabular}

NOTE: These are the targets that our baseline calibration of the model aims to reproduce. Most of these targets correspond to empirical moments in the United States. Each one of the first five targets pins down parameters $\{\beta, y, \delta, \gamma, b\}$. The remaining four targets collectively pin down the rest of parameters $\{A, a, k, \theta\}$.

Table 4 reports the calibrated values of the parameters $\{A, a, k, \theta\}$ in which the targeted wage dispersion is $W D 90 .{ }^{19}$ The values in the first column correspond to the baseline calibration, as described above. The remaining four columns correspond to the alternative calibrations in which the targets for the key parameters $b, \gamma, \theta$ and $a$ are changed. These four parameters are crucial for understanding the effects of inflation on the wage dispersion. Equation (12) shows that the low wage is a weighted average of the UI benefits $b$ and the high wage $w^{h}$. With a lower value of $b$, the same change in inflation imposes a greater downward pressure on the low wage relative to the high wage and thus results in a wider wage dispersion. ${ }^{20}$ When we increase the value of $\gamma$, it becomes more costly to produce goods in the goods market; with other things equal, this costliness reduces the real profits of firms and generates a stronger spillover effect into the labor market. Thus, the low wage becomes more responsive to the same change in inflations and the wage dispersion becomes larger. Likewise, an increase in the mark-up ratio in the goods market reduces the quantity of goods traded in the DM, which reduces the incentives of firms to post vacancies and

\footnotetext{
${ }^{19}$ The results are available upon request for the calibrated values of the parameters associated with other measures of the wage dispersion.

${ }^{20}$ We have explained in the discussion below Proposition 2 why the spillover effect on the low wage decreases with $b$.
} 
translates into a higher unemployment rate (larger spillover effect). Finally, an increase in the elasticity of the real demand for money with respect to the nominal interest rate implies that real money holding becomes more responsive to changes in inflation. Thus, with all else equal, an increase in inflation imposes a stronger downward pressure on the demand for real money that is carried forward to the DM. As a result, the quantity of goods traded in the DM drops, which reduces the real profits of the firm and decreases job openings in the labor market through the spillover effect. Because of the importance of these four parameters, we depart from the baseline calibration by changing their targets in the robustness check.

\begin{tabular}{|c|c|c|c|c|c|c|}
\hline \multicolumn{7}{|c|}{$\begin{array}{l}\text { Table } 4 \\
\text { Parameter Values }(W D 90)\end{array}$} \\
\hline & \multirow[t]{2}{*}{ Baseline } & \multicolumn{2}{|c|}{ Benefits } & \multirow[t]{2}{*}{ Curvature } & \multirow[t]{2}{*}{ Markup } & \multirow[t]{2}{*}{ Elasticity } \\
\hline & & $b=0.25$ & $b=0.4$ & & & \\
\hline$a$ & 0.3207 & 0.3248 & 0.3303 & 0.2787 & 0.3394 & 0.2104 \\
\hline$A$ & 1.0544 & 1.0372 & 1.0114 & 1.18777 & 1.0738 & 1.1604 \\
\hline$k$ & 3.9313 & 4.6278 & 5.1840 & 4.02617 & 4.0050 & 3.9292 \\
\hline$\theta$ & 0.6279 & 0.6348 & 0.6428 & 0.55267 & 0.5678 & 0.5084 \\
\hline
\end{tabular}

NOTE: Table 4 reports the calibrated values of $\{A, a, k, \theta\}$, in which the wage dispersion target is $W D 90$. In the "Baseline" column, the parameters are set to match the moments listed in Table 3. In the "Benefits", "Curvature", "Markup", and "Elasticity" columns, the targets for the parameters $b, \gamma, \theta$ and $a$ are changed. In the "Benefits" column, the UI benefits are set at the effective UI replacement rate $b=0.25$ and the statutory UI replacement ratio $b=0.4$. In the "Curvature" column, $\gamma$ is set to 1.1. In the "Markup" column, $\theta$ is determined to match the mark-up rate of 0.4 . In the "Elasticity" column, $a$ is determined to match the elasticity of the real demand for money with respect to nominal interest rate of -1 .

In the second column of Table 4, which is termed Benefits, $b$ is set at 0.25 and 0.4. In the third column, which is termed Curvature, $\gamma$ is set to 1.1. In the fourth column, which is termed Markup, $\theta$ is determined to match the mark-up rate of 0.4 rather than 0.3 . In the last column, which is termed Elasticity, $a$ is determined to match the elasticity of the real demand for money with respect to nominal interest rate of -1 rather than -0.556 . The intuition discussed above suggests that the predicted impacts on the wage dispersions should decrease in the case of Benefits and increase in the remaining three cases. It should be noted 
that although these alternative targets are arbitrarily set, they are useful for illustrating how the results depend on the parameter values.

\subsection{Results}

Using the calibrated parameters, Table 5 summarizes the responses of the wage dispersion $w^{h} / w^{l}$ in various cases when inflation doubles. For comparison purposes, we report in the last column the estimated elasticity of the (residual) wage dispersion with respect to inflation as presented in Table 2. It is evident that the model-predicted effects on the wage dispersion are both qualitatively and quantitatively consistent with their empirical counterparts. In the calibration where the targeted wage dispersion is measured by $W D 90$, in response to a 100 percent increase in inflation, the low wage decreases by $4.87 \%$, whereas the high wage decreases only by $2.70 \%$. The resulting wage dispersion increases by $2.17 \%$, which is fairly close to the elasticity of 2.22 estimated using the CPS data. In the other three cases where the targeted wage dispersions are measured by $W D 85, W D 80$, and $W D 75$, respectively, the calibrated model can explain a large proportion of the estimated reactions of the wage dispersion to inflation; the explanatory powers are $85.1 \%, 64.6 \%$, and $55.0 \%$, respectively.

\begin{tabular}{lccccc}
\hline \hline $\begin{array}{l}\text { Table } 5 \\
\text { Responses of Wage Dispersions }\end{array}$ & & & & \\
\hline & Baseline & Curvature & Markup & Elasticity & Data \\
\hline $\begin{array}{l}\text { Panel A: WD } 90 \\
\text { elas.of }\left(w^{h} / w^{l}\right) \text { w.r.t. } \pi(\%)\end{array}$ & 2.17 & 3.02 & 2.83 & 4.15 & 2.22 \\
$\begin{array}{l}\text { Panel B: WD } 85 \\
\text { elas.of }\left(w^{h} / w^{l}\right) \text { w.r.t. } \pi(\%)\end{array}$ & 1.49 & 2.78 & 1.95 & 2.87 & 1.75 \\
$\begin{array}{l}\text { Panel C: } \mathrm{WD} 80 \\
\text { elas.of }\left(w^{h} / w^{l}\right) \text { w.r.t. } \pi(\%)\end{array}$ & 1.04 & 1.45 & 1.37 & 2.01 & 1.61 \\
$\begin{array}{l}\text { Panel D: } \mathrm{WD} 75 \\
\text { elas.of }\left(w^{h} / w^{l}\right) \text { w.r.t. } \pi(\%)\end{array}$ & 0.72 & 1.00 & 0.94 & 1.39 & 1.31 \\
\hline \hline
\end{tabular}

NOTE: The predicted elasticity of the wage dispersion with respect to inflation in the baseline calibration is summarized in the "Baseline" column. The empirical counterpart is reported in the last column. The remaining three columns report the predicted elasticity when the calibration targets for the parameters $\gamma, \theta$ and $a$ are changed. 
Consistent with the intuition explained above, when we deviate from the baseline calibration by increasing the convexity of the cost function, the make-up ratio, or the elasticity of demand for real money, Table 5 shows that the predicted adjustment of the wage dispersion increases to $3.02 \%, 2.83 \%$ and $4.15 \%$, respectively, in the case of $W D 90$. A similar pattern is observed in the other three cases with different measures of wage dispersions.

\begin{tabular}{|c|c|c|c|c|}
\hline \multicolumn{5}{|c|}{$\begin{array}{l}\text { Table } 6 \\
\text { Responses of Wage Dispersions with UI Benefits }\end{array}$} \\
\hline & \multirow[t]{2}{*}{ Baseline } & \multicolumn{2}{|c|}{ Benefits } & \multirow[t]{2}{*}{ Data } \\
\hline & & $b=0.25$ & $b=0.4$ & \\
\hline $\begin{array}{l}\text { Panel A: WD } 90 \\
\text { elas.of }\left(w^{h} / w^{l}\right) \text { w.r.t. } \pi(\%)\end{array}$ & 2.17 & 1.85 & 1.39 & 2.22 \\
\hline $\begin{array}{l}\text { Panel B: WD } 85 \\
\text { elas.of }\left(w^{h} / w^{l}\right) \text { w.r.t. } \pi(\%)\end{array}$ & 1.49 & 1.29 & 1.05 & 1.75 \\
\hline $\begin{array}{l}\text { Panel C: WD } 80 \\
\text { elas.of }\left(w^{h} / w^{l}\right) \text { w.r.t. } \pi(\%)\end{array}$ & 1.04 & 0.89 & 0.75 & 1.61 \\
\hline $\begin{array}{l}\text { Panel D: WD } 75 \\
\text { elas.of }\left(w^{h} / w^{l}\right) \text { w.r.t. } \pi(\%)\end{array}$ & 0.72 & 0.61 & 0.51 & 1.31 \\
\hline
\end{tabular}

NOTE: Setting the UI benefits to alternative values, such as the statutory UI replacement ratio and the effective UI replacement ratio, has a negative effect on the predicted elasticity of the wage dispersion with respect to inflation.

We next explore the quantitative importance of the UI benefits. In particular, we examine the response of wage dispersion (to a 100 percent increase in inflation) when we change the UI benefits from zero to 0.25 and 0.4 . Consistent with the intuition provided above, Table 6 shows that increasing UI benefits reduces the predicted elasticities, but the results remain qualitatively valid. In the case of $W D 90$, increasing benefits to 0.25 reduces the predicted elasticity from 2.17 to 1.85 , and the model is able to account for $83.3 \%(=1.85 / 2.22)$ of the estimated elasticity. An increase in benefits to 0.4 further reduces the elasticity to 1.39 , while the model can still explain approximately $62.6 \%(=1.39 / 2.22)$ of the estimated response of the wage dispersion to inflation. Although increasing the UI benefits reduces the predicted reactions of the wage dispersion, using alternative calibration targets for the parameters $\gamma$, $\theta$ and $a$ can restore the predicted elasticity. These results are reported in Table 7 in which the value of benefits is set at the effective replacement ratio of $b=0.25$. 


\begin{tabular}{|c|c|c|c|c|c|}
\hline $\begin{array}{l}\text { Table } 7 \\
\text { Responses of Wage Disper }\end{array}$ & ions with & Benefits a & ad Alter & ative Tar & \\
\hline & $\begin{array}{l}\text { Benefits } \\
b=0.25\end{array}$ & Curvature & Markup & Elasticity & Data \\
\hline $\begin{array}{l}\text { Panel A: WD } 90 \\
\text { elas.of }\left(w^{h} / w^{l}\right) \text { w.r.t. } \pi(\%)\end{array}$ & 1.85 & 2.58 & 2.43 & 3.51 & 2.22 \\
\hline $\begin{array}{l}\text { Panel B: WD } 85 \\
\text { elas.of }\left(w^{h} / w^{l}\right) \text { w.r.t. } \pi(\%)\end{array}$ & 1.29 & 1.80 & 1.69 & 2.47 & 1.75 \\
\hline $\begin{array}{l}\text { Panel C: WD } 80 \\
\text { elas.of }\left(w^{h} / w^{l}\right) \text { w.r.t. } \pi(\%)\end{array}$ & 0.89 & 1.26 & 1.16 & 1.71 & 1.61 \\
\hline $\begin{array}{l}\text { Panel D: WD } 75 \\
\text { elas.of }\left(w^{h} / w^{l}\right) \text { w.r.t. } \pi(\%)\end{array}$ & 0.61 & 0.85 & 0.79 & 1.16 & 1.31 \\
\hline
\end{tabular}

NOTE: Setting the UI benefits to the effective UI replacement ratio reduces the model's explanatory power. However, changing the calibration targets for $\gamma, \theta$ and $a$ can improve the model's fit.

In the above simulations, we do not consider UI taxes. That is, we assume that the UI benefits are financed by some government programs outside of the model economy. In what follows we consider an alternative UI system in which the UI benefit payments received by the unemployed are fully financed by the UI taxes paid by the employed workers. Specifically, we consider two types of UI taxes: lump-sum and proportionate taxes.

Table 8 summarizes the results with the benefits at the effective replacement ratio of $b=0.25$. Apparently, introducing lump-sum taxes moves the model's predictions closer to their empirical counterparts, while allowing for proportionate taxes reduces the predicted elasticity. For instance, in the case of $W D 90$, the response of wage dispersion increases from $1.85 \%$ to $2.15 \%$ when the UI taxes are introduced in a lump sum fashion, while the predicted elasticity drops to $1.39 \%$ when the UI taxes are proportionate to the wages.

The intuition behind the results in Table 8 is as follows. In the case of the lump sum taxes, the percentage decrease in the low wages is larger than that of the high wages. Indeed, our simulation shows that the average reduction in the low wages is $17.2 \%$, while the counterpart for the high wage is only $8.16 \%$. As shown by Equation (12), the additional percentage reduction in the low wage relative to the high wage is equivalent to a reduction in the UI benefits $b$. As explained in Proposition 2, the negative spillover effect on the low wage decreases with $b$. Hence, compared with the baseline case without the UI taxes, the low wage 
responds much more than the high wage, which leads to a higher predicted elasticity, in line with the results shown in Table 6.

\begin{tabular}{|c|c|c|c|c|}
\hline \multicolumn{5}{|c|}{$\begin{array}{l}\text { Table } 8 \\
\text { Responses of Wage Dispersions with and without UI Taxes }\end{array}$} \\
\hline & \multicolumn{3}{|c|}{ Benefits $b=0.25$} & \multirow[t]{2}{*}{ Data } \\
\hline & No UI taxes & Lump sum & Proportionate & \\
\hline $\begin{array}{l}\text { Panel A: WD } 90 \\
\text { elas.of }\left(w^{h} / w^{l}\right) \text { w.r.t. } \pi(\%)\end{array}$ & 1.85 & 2.15 & 1.39 & 2.22 \\
\hline $\begin{array}{l}\text { Panel B: WD } 85 \\
\text { elas.of }\left(w^{h} / w^{l}\right) \text { w.r.t. } \pi(\%)\end{array}$ & 1.29 & 1.44 & 1.13 & 1.75 \\
\hline $\begin{array}{l}\text { Panel C: WD } 80 \\
\text { elas.of }\left(w^{h} / w^{l}\right) \text { w.r.t. } \pi(\%)\end{array}$ & 0.89 & 0.96 & 0.82 & 1.61 \\
\hline $\begin{array}{l}\text { Panel D: WD } 75 \\
\text { elas.of }\left(w^{h} / w^{l}\right) \text { w.r.t. } \pi(\%)\end{array}$ & 0.61 & 0.65 & 0.56 & 1.31 \\
\hline
\end{tabular}

NOTE: When lump sum UI taxes are introduced to rebalance the UI budget, changes in inflation have a larger effect on the wage dispersion relative to the case where the UI system is financed by some program outside of the model economy. When the UI taxes are replaced with a proportionate tax, the effect becomes smaller.

In the case of the proportionate UI taxes, the predicted elasticity becomes smaller because the negative spillover effect on the low wage becomes weaker. Note that in this case, the percentage changes in low and high wages are the same, which suggests that the high wage decreases more than the low wage in level. Hence, the decrease in real profits (equal to high wages) becomes larger than the baseline case without the UI taxes, which translates into an even lower job finding rate $\lambda_{2}^{h}$ through the spillover effect. ${ }^{21}$ As noted previously, a reduced $\lambda_{2}^{h}$ affects the two terms of Equation (12) in opposing directions; the first term with $b$ increases, while the second term with $w^{h}$ decreases. With a lower $\lambda_{2}^{h}$ resulting from proportionate taxes, it is easy to see that the gap between these two terms becomes smaller, which suggests that, compared with the baseline case without the UI taxes, the overall spillover effect on the low wage becomes weaker, although it remains negative. As a result, the low wage reacts less to changes in inflation, which leads to a lower predicted elasticity.

\footnotetext{
${ }^{21}$ Consistent with this intuition, a closer look at the predicted response of $\lambda_{2}^{h}$ shows that $\lambda_{2}^{h}$ decreases substantially from 0.0828 in the baseline case to 0.0279 in the case with the proportionate taxes.
} 


\section{Conclusion}

In this paper, we propose a novel mechanism to explain the observed empirical relationship between inflation and residual wage dispersion. CPS data for the period from $1994-2008$ suggest that inflation has a positive effect on the residual wage dispersion among homogenous workers. To explain this phenomenon, we extend the work of Berentsen et al.(2011) by incorporating uncoordinated job searches and by implementing the Mortensen rule in the wage determination process. Qualitatively and quantitatively, the predictions of our model are consistent with observed adjustments of the residual wage dispersion in response to changes in inflation. The intuition behind our result is as follows: an increase in inflation reduces the real profits of firms, which reduces the high wage. In equilibrium, the low wage is a weighted average of the high wage and UI benefits. Therefore, the low wage also decreases. This result is the direct effect of inflation on the low wage. In addition, inflation further reduces the low wage through an indirect effect; the lower real profits cause firms to post fewer vacancies, which translates into a tighter labor market. As a result, unemployed workers are less likely to find jobs. This outcome reduces the weight of the high wage and increases the weight of UI benefits, which places additional downward pressure on the low wage when the UI benefits are sufficiently small. Consequently, the low wage declines more than the high wage, which leads to increased wage dispersion. 


\section{Appendix}

\subsection{Figures}

\section{Figure 1: Inflation and Wage Dispersion}
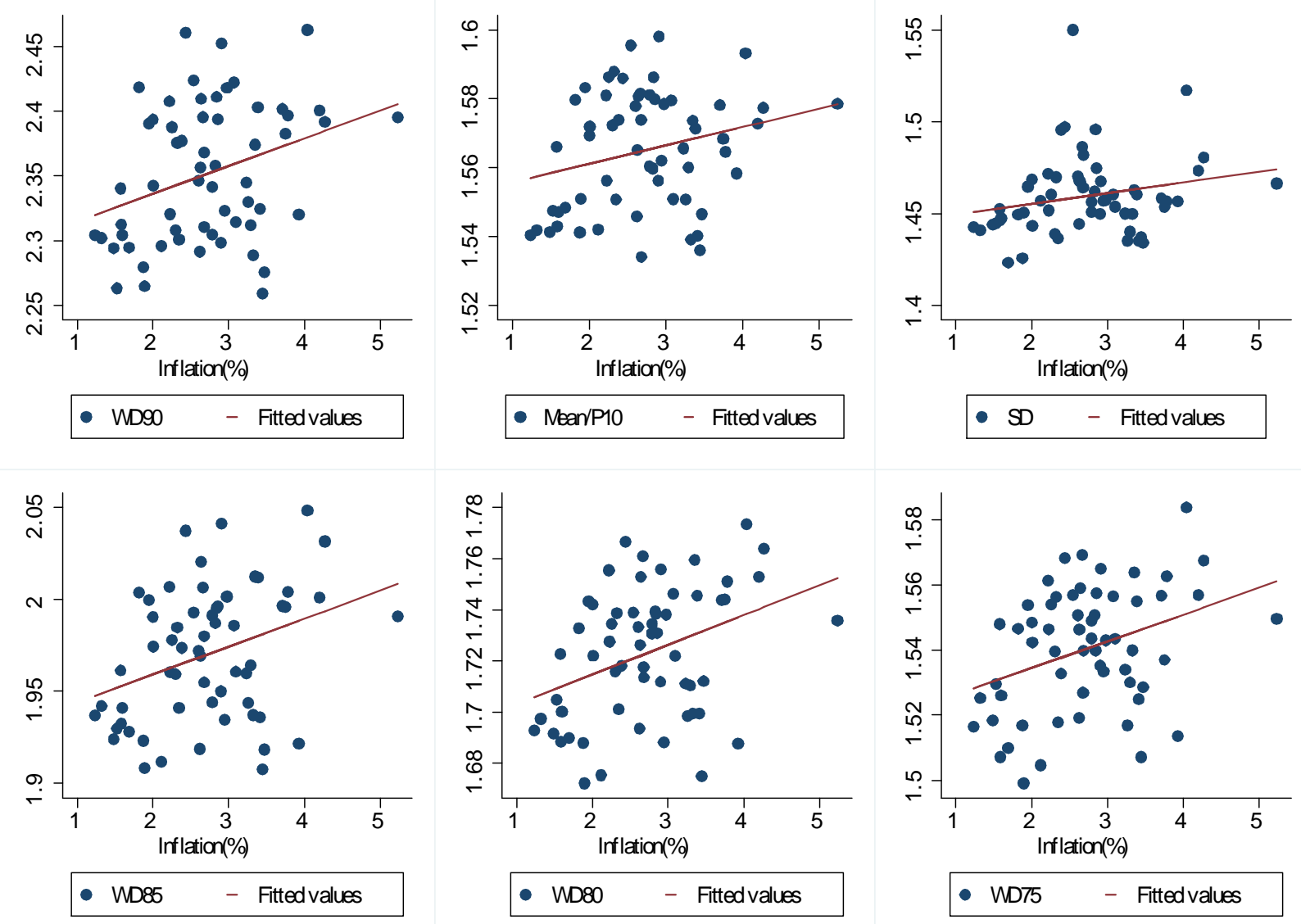

NOTE: Figure 1 shows a robust positive relationship between the residual wage dispersion and inflation. WD90, WD85, WD80, and WD75 are four measures of residual wage dispersion calculated as the ratio of high wages $(90 t h, 85 t h, 80 t h$ and $75 t h$ percentile of the residual wage distribution, respectively) to low wages (10th, 15th, 20th and $25 t h$ percentile of the residual wage distribution, respectively). Mean/P10 refers to the $50 t h-10 t h$ percentile wage gap. $S D$ stands for the standard deviation of the residual wage distribution. 


\section{Figure 2: Inflation and Wage Dispersion (correlation)}
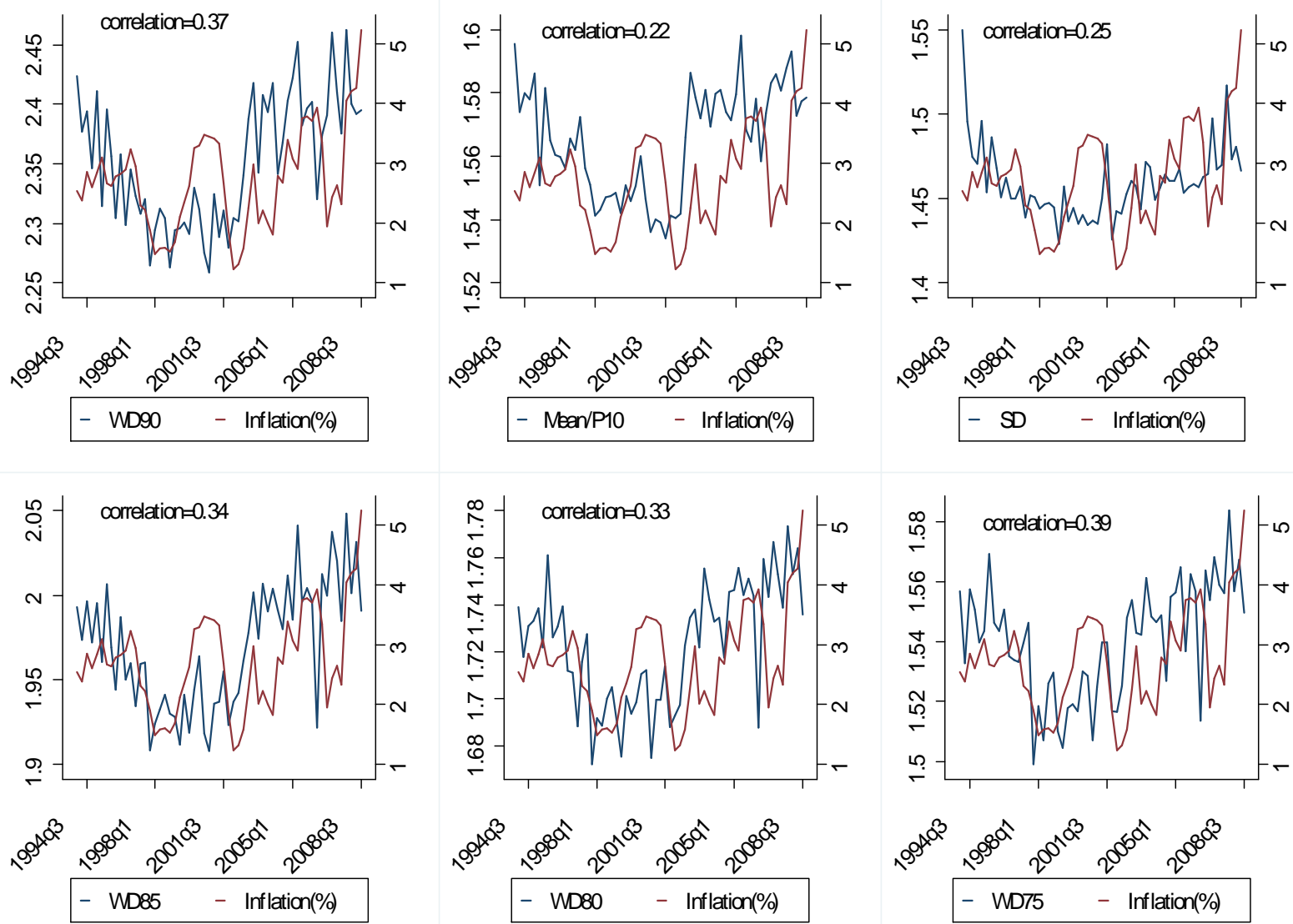

NOTE: Figure 2 shows a robust positive relationship between the residual wage dispersion and inflation, and the correlations between these two variables are reported. WD90, WD85, WD80, and WD75 are four measures of the residual wage dispersion calculated as the ratio of high wages $(90 t h, 85 t h, 80 t h$ and $75 t h$ percentile of the residual wage distribution, respectively) to low wages $(10 t h, 15 t h, 20 t h$ and $25 t h$ percentile of the residual wage distribution, respectively). Mean $/ P 10$ refers to the $50 t h-10 t h$ percentile wage gap. $S D$ stands for the standard deviation of the residual wage distribution.

\section{Figure 3: Timing}

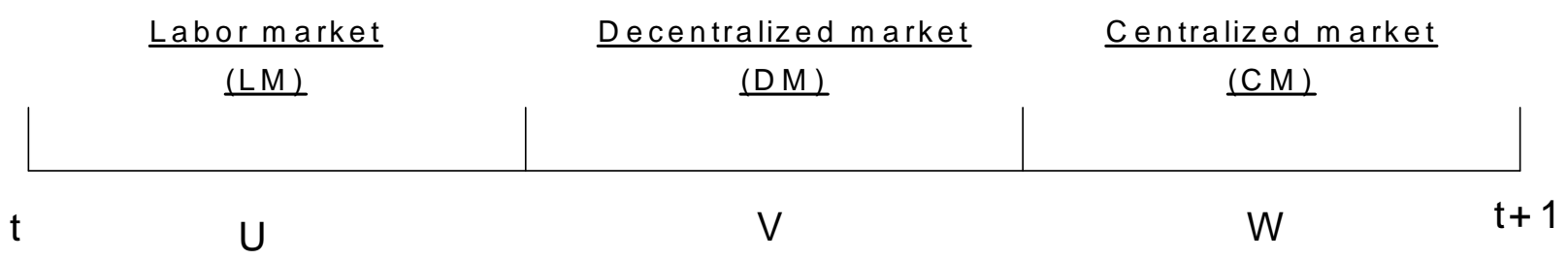




\section{Figure 4: Monetary Equilibrium}

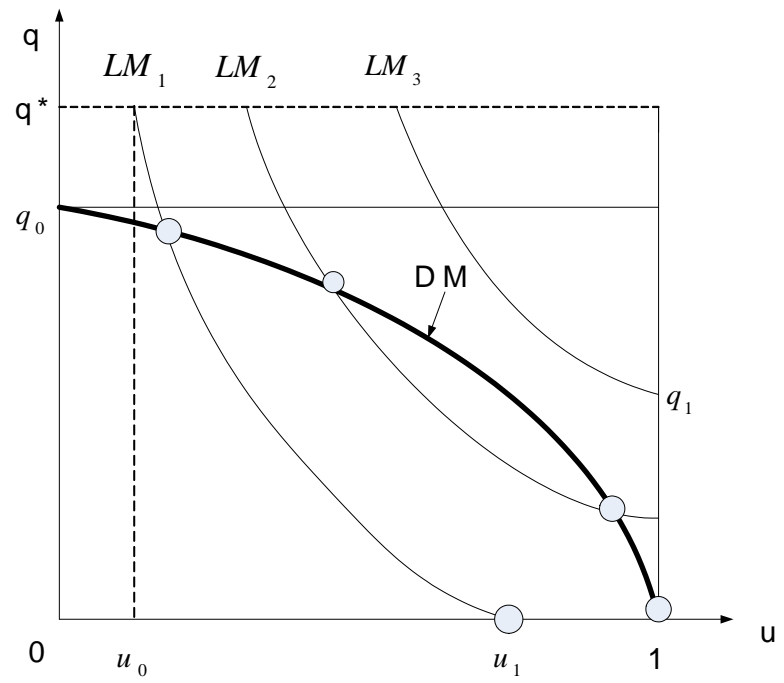

\subsection{The Current Population Survey}

The Current Population Survey (CPS) is a monthly survey of approximately 50,000 workers conducted by the Bureau of the Census for the Bureau of Labor Statistics. The survey has been conducted for more than 50 years. To be eligible to participate in the CPS, individuals must be at least 15 years of age and must not serve in the Armed Forces. In general, one person ("reference person") responds on behalf of all eligible members of the family.

The original data set contains more than 200,000 person-level observations per month. To create our sample, we exclude all individuals who report zero hourly wages in their main job and individuals whose hourly wages are top-coded (i.e., greater than \$99). We then obtain approximately 2,000 individual observations per month during the period from 1994 to 2008 .

\subsection{Proofs}

Proof of Nash bargaining problem in the DM must satisfy $d=z$.

Lagos and Wright (2005) provide a rigorous proof of why buyers should not bring "idle" money balances into the DM as long as we are not in the extreme case of $i=0$ (Friedman rule) and $\theta=1$. We follow the same argument and show that $d=z$ as follows. 
The Nash bargaining problem in the DM is

$$
\max _{q, d}[v(q)-\rho d]^{\theta}[\rho d-q]^{1-\theta}
$$

s.t. $d \leq z$ and $q \leq y$,

The solution to $(8)$ is

$$
\begin{aligned}
& q= \begin{cases}\hat{q} & \text { if } z<z^{*} \\
q^{*} & \text { if } z \geq z^{*}\end{cases} \\
& d= \begin{cases}z & \text { if } z<z^{*} \\
z^{*} & \text { if } z \geq z^{*}\end{cases}
\end{aligned}
$$

where $\hat{q}$ is the $q$ that solves $\rho z=g(q)$, with

$$
g(q) \equiv \frac{\theta v^{\prime}(q) q+(1-\theta) v(q)}{\theta v^{\prime}(q)+1-\theta}
$$

and $z^{*}=g\left(q^{*}\right) / \rho$, where $v^{\prime}\left(q^{*}\right)=1$. In words, if the buyer's cash is at least $z^{*}$, the constraint $d \leq z$ is not binding and he receives $q^{*}$ for $z^{*}$ dollars; otherwise, the constraint is binding and he spends all of his money and to receives $\hat{q}$. We can now use these results to solve the maximization problem in Equation (5) on page 17 of the paper as follows:

$$
\max _{\hat{z}}\left\{\beta \hat{\alpha}^{h}[v(\hat{q})-\hat{\rho} \hat{d}]-\hat{z}(1-\beta \hat{\rho})\right\}
$$

The first-order-condition wrt to $\hat{z}$ becomes

$$
-(1-\beta \hat{\rho})+\beta \hat{\alpha}^{h}\left\{v^{\prime}\left[(\hat{q}(\hat{z})] * \hat{q}^{\prime}(\hat{z})-\hat{\rho} \hat{d}^{\prime}(\hat{z})\right\}=0\right.
$$

Notice that $v^{\prime}\left[(\hat{q}(\hat{z})] * \hat{q}^{\prime}(\hat{z})-\hat{\rho} \hat{d}^{\prime}(\hat{z})\right.$ is zero for all $\hat{z} \geq z^{*}$ by $(19)$. Hence, $\beta \rho>1$ implies that the problem of choosing $\hat{z}$ in Equation (20) has no solution, because the objective function is strictly increasing for all $\hat{z} \geq z^{*}$. This result means that any equilibrium must satisfy $\beta \rho \leq 1$. Therefore, the minimum inflation rate consistent with equilibrium is $1 / \rho=1+\pi=\beta$, which 
is the Friedman rule. Given $\beta \rho \leq 1$, the objective function in (20) is nonincreasing in $\hat{z}$ for $\hat{z} \geq z^{*}$.

The slope of the objective function in (20) as $\hat{z} \rightarrow z^{*}$ from below is proportional to $-(1-\beta \hat{\rho})+\beta \hat{\alpha}^{h} \Sigma$, where

$$
\Sigma=\frac{v^{\prime}\left(q^{*}\right)^{2}}{v^{\prime}\left(q^{*}\right)^{2}+\theta(1-\theta)\left[v\left(q^{*}\right)-c\left(q^{*}\right)\right]\left[c^{\prime \prime}\left(q^{*}\right)-v^{\prime \prime}\left(q^{*}\right)\right]}-1
$$

is the worker's marginal gain from bringing an additional dollar into the DM evaluated at $q=q^{*}$. Note that $\Sigma \leq 0$ and the inequality is strict except when $\theta=1$. Thus, unless $\beta \rho=1$ and $\theta=1$, the slope of the objective function in (20) as $\hat{z} \rightarrow z^{*}$ is strictly negative, and therefore any solution must satisfy $\hat{z}<z^{*}$. This completes the proof of the claim that $d=z$ as long as we are not in the extreme case of $\beta \rho=1$ and $\theta=1$.

Proof of Proposition 1. A differentiation of (10) wrt the nominal interest rate, $i$, shows that $\frac{d q}{d i}<0$ for a given $u$. Both the LM and the DM curves are downward sloping. Given this result and considering that any change in $i$ will not shift the LM curve (see Equation (16)), we infer that an increase in $i$ (which is equivalent to an increase in the inflation rate) will cause a decrease in $q$ and an increase in $u$.

Proof of Proposition 2. Because differentiating (17) does not provide us with closed-form solutions, we divide the analysis into two steps. First, we examine an alternative expression of (17) to gain a better understanding of how inflation affects the wage dispersion and wage levels. We define $\widetilde{W D}$ as

$$
\widetilde{W D}=\frac{w^{h}-b}{w^{l}-b}
$$

Substituting for $w^{h}$ and $w^{l}$ using equations (11) and (12) and then simplifying the results, we obtain

$$
\widetilde{W D}=\frac{1-\beta\left(1-\delta-e^{-\phi}\right)}{\beta e^{-\phi}}
$$

It is immediately obvious that $u$ is the only steady-state variable that appears in (22). To consider the effects of inflation on $\widetilde{W D}$, we only need to consider the effect of increased 
inflation on the steady-state equilibrium value of $u$. It is routine to show that

$$
\frac{\partial \widetilde{W D}}{\partial i}>0
$$

In the second step, we use the above result to solve for $\partial(W D) / \partial i$. There are two possible cases with regard to the effects of inflation on wage levels and wage dispersion.

Case 1. $w^{h}$ decreases with inflation. Because $\partial(\widetilde{W D}) / \partial i>0, w^{l}$ must also decrease. The effect on $W D$ (which is defined as $w^{h} / w^{l}$ ) is ambiguous. To examine this relationship closely, we rewrite $\widetilde{W D}$ as follows

$$
\widetilde{W D}=\frac{w^{h}-b}{w^{l}-b}=\frac{\frac{w^{h}}{w^{l}}-\frac{b}{w^{l}}}{1-\frac{b}{w^{l}}} .
$$

Rearranging and differentiating (23) wrt $i$ yields

$$
\frac{\partial\left(\frac{w^{h}}{w^{l}}\right)}{\partial i}=\left(1-\frac{b}{w^{l}}\right) \frac{\partial(\widetilde{W D})}{\partial i}-(\widetilde{W D}-1) \frac{\partial\left(\frac{b}{w^{l}}\right)}{\partial i}
$$

Because $b / w^{l} \leq 1$ and $\widetilde{W D} \geq 1$ and because $\partial(\widetilde{W D}) / \partial i>0$ and $\partial\left(b / w^{l}\right) / \partial i>0$, we still obtain ambiguous results in terms of $\partial\left(w^{h} / w^{l}\right) / \partial i$. However, (24) clearly indicates that when the value of $b$ is much smaller than $w^{l}, 1-b / w^{l}$ becomes larger and $\partial\left(w^{h} / w^{l}\right) / \partial i$ then becomes positive. The positive effect is maximized when $b=0$. Hence, we conclude that if $\partial\left(w^{h}\right) / \partial i<0$, then $\partial\left(w^{l}\right) / \partial i<0$ and $\partial\left(w^{h} / w^{l}\right) / \partial i>0$.

Case 2. $w^{h}$ increases with inflation. Now, $w^{l}$ can increase or decrease. If $w^{l}$ decreases, then $\partial\left(w^{h} / w^{l}\right) / \partial i>0$. In the case in which $w^{l}$ increases, (24) suggests that $\partial\left(w^{h} / w^{l}\right) / \partial i>0$ is still true. Therefore, we conclude that if $\partial\left(w^{h}\right) / \partial i>0$, then $\partial\left(w^{l}\right) / \partial i<0$ or $\partial\left(w^{l}\right) / \partial i>0$ and $\partial\left(w^{h} / w^{l}\right) / \partial i>0$. However, as explained above, with plausible parameter values, the real profits of firms $R$ always decrease with inflation; therefore, $w^{h}$ also declines with inflation. Case 2 is irrelevant.

In summary, we show that if $\partial\left(w^{h}\right) / \partial i<0$, then $\partial\left(w^{l}\right) / \partial i<0$ and $\partial\left(w^{h} / w^{l}\right) / \partial i>0$. 


\section{References}

[1] Acemoglu, D., 2002. Technical Change, Inequality, and the Labor Market. Journal of Economic Literature, 40(1): 7-72.

[2] Albrecht, J., Vroman, S., 2001. Equilibrium Search with Time-Varying Unemployment Benefits. Economic Journal 115, 631-648.

[3] Autor, D. H., Katz, L.F., Kearney, M.S., 2008. Trends in U.S. Wage Inequality: Revising and Revisionists. Review of Economics and Statistics 90, 300-323.

[4] Berentsen, A., Menzio, G., Wright, R., 2011. Inflation and Unemployment in the Long Run. American Economic Review 101, 371-398.

[5] Bulir, A., 2001. Income Inequality: Does Inflation Matter? IMF Staff Papers, Vol. 48, No. 1.

[6] Burdett, K., Mortensen, D., 1998. Wage Differentials, Employer Size, and Unemployment. International Economic Review 39, 257-273.

[7] Burdett, K., Shi, S, Wright, R., 2001. Pricing and Matching with Frictions. Journal of Political Economy 109, 1060-1085.

[8] Cao, M., Shi, S., 2000. Coordination, Matching, and Wages. Canadian Journal of Economics 33, 1009-1033.

[9] Card, D., DiNardo, J., 2002. Skill-Biased Technological Change and Rising Wage Inequality: Some Problems and Puzzles. Journal of Labor Economics 20 (4), 733-783.

[10] Cysne, R., Wilfredo, M., Monteiro, P., 2005. Inflation and Income Inequality: A shopping-Time Approach. Journal of Development Economics 78, 516-528.

[11] Diamond, P., 1993. Search, Sticky Prices, and Inflation. Review of Economic Studies 60, 53-68. 
[12] Erikson, C., Ichino, A., 1995. Wage Differentials in Italy: Market Forces and Institutions. R. B. Freeman and L. Katz, eds. Differences and Changes in Wage Structures (Chicago University of Chicago Press, 1995), 265-305.

[13] Faig, M., Jerez. B., 2005. A Theory of Commerce. Journal of Economic Theory 122, 60-99.

[14] Faig, M., Zhang, M., Zhang, S., 2015. Effects of Extended Unemployment Insurance Benefits on Labor Dynamics. Macroeconomic Dynamics. Published online January 14, 2015, 1-22.

[15] Garcia-Penalosa, C., Turnovsky, S., 2015. Income Inequality, Mobility, and the Accumulation of Capital. Macroeconomic Dynamics 19, 1332-1357.

[16] Hammermesh, D. 1986. Inflation and Labor Market Adjustment. Economica 53, 63-73.

[17] Hornstein, A., Krusell P., Violante G., 2007. Frictional Wage Dispersion in Search Models: A Quantitative Assessment. National Bureau of Economic Research Working Paper 13674 .

[18] Horstein, A., Krusell P., Violante G., 2011. Frictional Wage inequality in Search Models: A Quantitative Assessment. American Economic Review 101, 2873-2898.

[19] Julien, B., Kennes, J., King, I., 2006. Residual Wage Disparity and Coordination Unemployment. International Economic Review 47 (3), 961-989.

[20] Julien, B., Kennes, J., King, I., 2011. Implementing the Mortensen Rule in a Frictional Labor Market. Journal of Macroeconomics 33, 80-91.

[21] Katz, L., Autor, D., Changes in the Wage Structure and Earnings Inequality. in O. Ashenfelter and D. Card, eds., Handbook of Labor Economics, Vol. 3 (Amsterdam: Elsevier Science B.V., 1999) chapter 26.

[22] Kumar, A., 2008. Inflation and the Dispersion of Real Wages. International Economic Review 49, 377-399. 
[23] Kunieda, T., Okada, K., Shibata, A., 2014. Finance and Inequality: How Does Globalization Change Their Relationship? Macroeconomic Dynamics 18, 1091-1128.

[24] Lagos, R., Wright, R., 2005. A Unified Framework for Monetary Theory and Policy Analysis. Journal of Political Economy 113, 463-484.

[25] Lemieux, T., 2006. Increasing Residual Wage Inequality: Composition Effects, Noisy Data, or Rising Demand for Skill?. American Economic Review 96, 461-498.

[26] McAfee, R., McMillan. J., 1987. Auctions and Bidding. Journal of Economic Literature Volume XXV, 699-738.

[27] Montgomery, J., 1991. Social Networks an Labor Market Outcomes: Toward an Economic Analysis. American Economic Review 81, 1408-1418.

[28] Mortensen, D., 1982. Efficiency of matching, racing and related games. American Economic Review 72, 968-979.

[29] Mortensen, D., Pissarides C., 1994. Job Creation and Job Destruction in the Theory of Unemployment. Review of Economic Studies 61, 397-416.

[30] Munshi, K., 2003. Networks in the Modern Economy: Mexican Migrants in the U.S. Labor Market. Quarterly Journal of Economics 118, 549-599.

[31] Ochs, J., 1990. The Coordination Problem in Decentralized Markets: An Experiment. The Quarterly Journal of Economics 105, 545-559.

[32] Pissarides, C., 1985. Short-Run Equilibrium Dynamics of Unemployment, Vacancies and Real Wage. American Economic Review 75, 676-690.

[33] Postel-Vinary, F., Robin, J. M., 2002. The Distribution of Earnings in an Equilibrium Search Model with State-Dependent Offers and Counter Offers. International Economic Review 43, 989-1016.

[34] Rogerson, R., Shimer, R., Wright, R., 2005. Search Theoretic Models of the Labor Market: A Survey. Journal of Economic Literature 43, 959-88. 
[35] Shi, S., 1997. A Divisible Search Model of Fiat Money. Econometrica 65, 75-102.

[36] Shi, S., 2002. Product Market and the Size-Wage Differential. International Economic Review 43, 21-54.

[37] Shimer, R., 2005. The Cyclical Behavior of Unemployment and Vacancies: Evidence and Theory. American Economic Review 95, 25-49.

[38] Topa, G., 2001. Social Interactions, Local Spillovers and Unemployment. Review of Economic Studies 68, 261-295.

[39] Wright, R., 2010. A Uniqueness Proof for Monetary Steady State. Journal of Economic Theory 145, 382-391.

[40] Zhang, M., Faig, M., 2012. Labor Market Cycles, Unemployment Insurance Eligibility, and Moral Hazard. Review of Economic Dynamics 15, 41-56. 